\title{
EXPERIMENTAL AND NUMERICAL INVESTIGATION OF THE RESPONSE OF GEOCELL-REINFORCED WALLS TO HORIZONTAL LOCALIZED IMPACT
}

\section{Authors:}

Maxime SOUDÉ $1,2,3$

Bastien CHEVALIER ${ }^{2,3}$

Michel GRÉDIAC ${ }^{2,3}$

Aurélie TALON ${ }^{2,3}$

Roland GOURVÈS ${ }^{1}$

Affiliations:

1 Sol Solution Géotechnique Réseaux - 63204 Riom Cedex, France

2 Clermont Université, Université Blaise Pascal, Institut Pascal, BP 10448, F63000 Clermont-Ferrand, France

3 CNRS, UMR 6602, Institut Pascal, F-63171 Aubière, France 
Abstract:

The aim of this work is to study the effect of a localized impact on a wall made of soil reinforced with geocells. First, two structures were tested with an impacting remote-controlled car. Such experiments, carried out on $1 / 10^{\text {th }}$-scale model structures for practical reasons, are designed to mimic the mechanical response of a alveolar geocell reinforcement system. Two types of constitutive materials were considered for the geocells with very different mechanical properties. The test structures were dismantled after the tests to analyse the influence of the impact on the cell layers, especially within their bulk. Examining the video of the tests captured with two highspeed cameras also helped understanding the phenomena that occurred during impact. These experiments were completed by numerical simulations whose objective was to understand more clearly the causes of the phenomena observed either within the dismantled structures or in the videos.

Keywords: geocell, geotextile, Discrete Element Method, impact load, smallscale model.

\section{INTRODUCTION}

The mechanical behaviours of soils reinforced with various types of inclusions such as geosynthetic sheets, steel armatures, geogrids, gabion cells and geocells have attracted attention from many researchers in the recent past (Chen et al., 2013; Moghaddas Tafreshi and Dawson, 2012; Parsons et al., 2009; Saran, 2010; Yang et al., 2012). In particular, the effect of dynamic loads on such structures is a major issue as far as hazard mitigation is concerned. Indeed loadings such as impacts, earthquakes, or blasts, involve complex phenomena that are not clearly understood. 

the literature (Huang et al., 2011; Koseki, 2012; Lee et al., 2010; Leshchinsky et al., 2009; Ling et al., 2009). In addition, standards such as Eurocode 8-5 (Eurocode 8, 2005) take into account the seismic loadings, considering them as additional equivalent static loads , as proposed by the pseudo-static Mononobe-Okabe method (Okabe, 1924; Mononobe and Matsuo, 1929).

Concerning the effect of blasts on reinforced soils, the papers which have been published so far mainly deal with numerical studies. Experimental studies are scarce (Chew et al., 2003). This is due to the fact that such experiments are generally risky and need highly specific resources. In addition, they are often performed within the framework of private or military investigations and therefore generally remain unpublished.

The case of impact loadings is more and more attractive in the literature though only the case of rockfall embankments has been addressed in practice until now (Nomura, 2002, Bertrand, 2005, Lambert, 2009, Bourrier, 2010, Bourrier, 2011). Furthermore, standards do not really take into account this type of loading because only the deforming capacities of the impacting structure (e.g., a vehicle) are considered in the case of shock rather than those of the impacted structure (Eurocode 1, 1991).

In this context, the aim of the present work is to examine the effect of a localized impact on soils reinforced with geocells. Such reinforced structures can potentially be used to protect pre-existing structures against impacts, so this type of study is necessary to investigate their capacity to provide protection.

Model tests were carried out instead of full-scale tests. The obvious reason is that they can be much more easily performed compared to full-scale tests, both in terms of cost and safety. In fact, full-scale tests can be considered as a final step of a sustainability study for a given solution. This objective is however out of the scope of 
the current study. Model tests constitute an essential preliminary stage for observing and understanding qualitatively the mechanisms involved, even in cases where the similarity laws are not satisfied. In the current study, it is too complex to fullfill similitude laws to provide a reliable relationship between model and full-scale responses. In this context, the aim of this study is to investigate the mechanisms involved and to reproduce them using Discrete Element Method (DEM) while assuming that similar behaviours are expected at normal scale. Two impact experiments were first carried out on geocell structures at a scale of $1 / 10^{\text {th }}$. Two materials featuring very different mechanical properties were chosen for alveolar reinforcement: paper and polymer. These experiments were captured by two high-speed cameras at the same time for thorough investigation of the phenomena occurring during the impacts. The models of reinforced structures were then dismantled and the deformation of the different layers was studied. Finally, numerical simulations were carried out to analyse the global and local mechanisms occurring in the reinforced structures. The results obtained from these experiments and the calculations used are presented and discussed in the different sections of the paper.

\section{EXPERIMENTAL STUDY}

\subsection{Materials and methods}

\subsubsection{Details of the test structures}

Two reinforced material structures were tested in this study. The difference between these two structures is due to the nature of the reinforcement. Each structure was composed of 19 layers of geocells filled with a specific material. In the horizontal plane, each layer was $120 \mathrm{~cm}$ in length, $55 \mathrm{~cm}$ in width and $2.5 \mathrm{~cm}$ in height (Fig.1).

The 3 layers at the bottom of the wall were placed below the ground surface. The total height of this laminated structure was about $47 \mathrm{~cm}$, including the anchoring layers. The 
whole structure was built up inside a U-shaped wood coffering, which constituted the boundary conditions of the model on three of its sides. This approach is similar to that used by Racana et al. (2003) wherein they have studied the response of similar structures under static loading. The current size of the cells is expected to mimic the response of an $\mathrm{M} 3 \mathrm{~S} \circledast$ system to the scale of $1 / 10^{\text {th }}$. Apart from the cells located in front of the structures which deformed during the filling and compaction stages, the shape of the cells located in the bulk was nearly square, even after compaction.

The intercellular bonds were formed by 2 staples placed along the width of the reinforcement strips. After filling, the length of the inner cells along the diagonal was about $5.5 \mathrm{~cm}$. They were square in shape whereas the cells located along the boundary were curved. The boundary conditions were made rigid. Before filling the cells, each layer was pre-extended with a wooden strap structure. After filling, the material was compacted twice: before and after the wooden straps were removed. This process was repeated successively for each additional layer placed on those built beforehand, thus giving rise to the desired model structure. were intended to provide very different mechanical responses. The first was an extruded polyethylene film (PE) with a thickness of $0.1 \mathrm{~mm}$. The second was greaseproof paper (GP).

\subsubsection{Mechanical properties of the alveolar reinforcement}

Two different reinforcements were studied, namely polymer and paper, which

Tensile tests were performed on both materials in order to characterize and underline their very different mechanical responses. The initial stiffness and strength were also determined because these quantities are used in the second part of this study dealing with the mechanical model. Two types of specimens were considered for each material: a single strip and two bonded strips. The size of the first type of specimen was 
$25 \times 200 \mathrm{~mm}^{2}$. The second type of specimen was made of two strips bonded at midlength. The strips were embedded in compression clamping devices. Tensile tests were conducted with a cross-head speed of $4 \mathrm{~mm} \cdot \mathrm{min}^{-1}$. A force transducer and an extensometer were employed to measure the applied tensile force and the global longitudinal elongation of the specimen, respectively. The mean strain and the tensile strength were then deduced from the force/elongation curves.

The responses of the different specimens to the tensile tests are shown in Fig.2. For the single strip specimens, it can be observed that the GP specimens exhibit a quasilinear elastic response with an initial stiffness of $250 \mathrm{kN} / \mathrm{m}$. The PE specimens have response presenting a linear phase with a stiffness of $16 \mathrm{kN} / \mathrm{m}$ followed by a yielding phase. Both bonded strip specimens exhibit a plastic response and a force at failure equal to $0.5 \mathrm{kN} / \mathrm{mm}$ and $0.25 \mathrm{kN} / \mathrm{mm}$, respectively. Observing the specimens after failure revealed that the strips tore gradually for GP whereas they deformed and plasticized for PE. and polystyrene micro-beads. The expanded clay particles presented a sub-spherical shape with diameters ranging from 0.5 to $2.5 \mathrm{~mm}$. The diameter of the polystyrene micro-beads ranged from 0.9 to $1.5 \mathrm{~mm}$. These dimensions are in agreement with those of the cells in terms of ratio between the size of actual fill materials that typically are expected to be used in full-scale structures, and the size of actual cells. Segregation during mixing was avoided by adding $10 \%$ in weight of glycerine. This led to a rubbing, light and compressible mixture. 
fill material, namely oedometric tests, direct shear tests and trench stability tests. These tests were performed with a material density of $450 \mathrm{~kg} / \mathrm{m}^{3}$, same as that of the fill material in the impact experiments.

\section{Young's modulus}

An order of magnitude of the Young's modulus was estimated from oedometer tests. The classic equation linking Young's modulus $E$, oedometric modulus $E_{\text {oed }}$ and Poisson's ratio $v$ was used to estimate the Young's modulus of this material from oedometer tests:

$$
E=E_{\text {oed }} \frac{(1+v)(1-2 v)}{1-v}
$$

Assuming the value of the Poisson's ratio is known, it is possible to assume a value of the Young's modulus from the value of the oedometric modulus using the above equation. The influence of crushing of the expanded clay particle on Young's modulus was not considered here since this value was used as an order of magnitude only.

An average value of the oedometric modulus $E_{\text {oed }}$ of $0.6 \mathrm{MPa}$ was obtained. For values of the Poisson's ratio ranging between 0.2 and 0.35 , the Young's modulus ranges between 0.4 and $0.55 \mathrm{MPa}$ (Eq. 1).

\section{Shear strength characterization}

Direct shear tests were performed on circular specimens of $6 \mathrm{~cm}$ diameter and $2 \mathrm{~cm}$ thickness. The shear tests were conducted up to a maximum displacement of $5 \mathrm{~mm}$ and with vertical confining pressures between 1.4 and $21.7 \mathrm{kPa}$. An internal friction angle $\varphi$ of $44^{\circ}$ and a cohesion $c$ of $5 \mathrm{kPa}$ were deduced from these tests. The confining 
pressure used were lower than those which are likely to appear in the impact experiment, so the friction angle given here should represent a upper limit value.

\subsubsection{Impacting vehicle}

The impact velocity and the geometry of the impacting interface were keyparameters in this experiment. A remote-controlled vehicle was chosen as the impacting device to ensure precise control of the velocity as impact occurred. In addition, a cylindrical steel rod was fixed on the front of the vehicle. This was made to adjust the location of the impact precisely and increase the moment for a given speed.

The size of the front rod fitted the size of the cells: diameter $d=5 \mathrm{~cm}$ and length $L=18 \mathrm{~cm}$. Two similar vehicles were prepared: one for each type of reinforced soil structure, since the vehicles were non-reusable after impact. The weight of each vehicle was $5 \mathrm{~kg}$ including the front rod. The speed of the vehicle during impact time was set to $10 \mathrm{~m} \cdot \mathrm{s}^{-1}$. The modelled impact is found to be equivalent to a vehicle of 5 tons with a speed of $110 \mathrm{~km} / \mathrm{h}$ at full scale.

\subsubsection{High-speed video cameras}

Two high-speed video cameras were used to track the vehicles during each impact (Fig.3). Camera Nr.1 was a Fastcam-APX 120K. It captures 1600 frames/second with a sensor resolution of $1024 \times 768$ pixels. This camera was placed in such a way that it recorded the impact with an open angle view. It was located $2.5 \mathrm{~m}$ above ground level. Camera Nr.2 was a black and white Photron APX 1024x512 pixels placed directly at ground level. It recorded the impact from a lateral viewpoint. Its sensor resolution is the same as that of the other camera but it records 4000 frames/second. Both vehicles were equipped with patched targets on their lateral side to deduce their location, velocity and acceleration in time from footage analysis. 


\subsection{Results and discussion}

\subsubsection{Global analysis}

The readers of the electronic version of this paper are invited to watch the videos available on the website of the Journal. Both videos enable us to observe and analyse each impact. First the rod penetrated into the structure. The distance travelled within the structure was only a few centimetres: $13 \mathrm{~cm}$ for the GP reinforced structure and $17.3 \mathrm{~cm}$ for the PE one. The deformation spread from the impact zone to the top free boundary by pushing a cone-shaped part of the reinforced structure. This phenomenon is visible in Fig.4. After having reached its maximal penetration, the vehicle moved back slightly and slowly compared to the speed reached just before the impact occurred. It can be noted that despite the rather considerable deformation of the layers, whose vertical deflection reached a few centimetres for both structures, all the layers returned to their initial location and geometry apart from the failed cell walls (see below). Finally, it was observed that this phenomenon was localized since the cells located further from the impact zone, near the lateral walls for instance, did not move.

\subsubsection{Local analysis after impact and dismantling the reinforced structure}

The structures were dismantled layer by layer after the impact. The topography of each layer was measured by collecting the location of the nodes of a virtual mesh with a pitch of $5 \mathrm{~cm}$ in both horizontal directions. These data enabled us to draw crosssections of the deformed structures along both the vertical and horizontal planes and deduce the internal deformation of the structures. It was assumed here that the compaction of a layer did not affect the vertical location of the ones previously installed. It must be noted that the impacting vehicles were not removed from the 
reinforced structures after impact. The zones of the structures affected by the impact were clearly identified. Several conclusions can be drawn from this dismantling stage:

- a Coulomb wedge can be clearly identified. It starts at the impact zone and spreads toward the top free boundary (Fig.4);

- it is interesting to note that except for the layer located at the level of the impact, the other layers behave as a whole. This is due to the fact that the reinforcement is regularly spatially distributed and spreads the deformation due to the impact within the layers, thus underlining the very positive effect of the reinforcement. This phenomenon is clearer in the PE-reinforced structure than in the GP-reinforced one. It is also interesting to note that this deformation becomes increasingly less in the layers located further from this plane (Fig.5);

- the layer located at the level of the impact exhibits a specific response. A significant number of failed GP strips (54) were observed, in particular along the impact direction. On the other hand, only 4 polymeric strips failed. The failed strips are located in a zone defined by the black solid lines in Fig.6. These failed strips are nearly symmetrical with respect to the vertical mid-plane of the rod.

\subsubsection{Penetration, speed and acceleration of the impacting vehicles}

It was possible to measure the displacement of the targets placed on the vehicles by processing the videos provided by the lateral high-speed camera. The axis of the camera pointed perpendicularly to the trajectory of the vehicle and focused on the impact zone. In addition, it was placed far enough from the targets. Thus, no corrections were made on the displacement measurements due to view angle. The velocity and the acceleration can thus be obtained by single and double numerical derivation, 
respectively. Speed vs. time is plotted in Fig.7. It can be seen that the penetration of the impacting vehicle regularly increases for both types of structures up to a maximum value of $18 \mathrm{~cm}$ and $14 \mathrm{~cm}$ for the GP- and the PE-reinforced structures, respectively. The initial speed is the same for both tests. It rapidly decreases since the impact lasts only approximately $28 \mathrm{~ms}$ for the PE- structure and $40 \mathrm{~ms}$ for the GP-reinforced structure.

This information is also confirmed by the deceleration curves shown in Fig.8. The deceleration peak equals $400 \mathrm{~m} . \mathrm{s}^{-2}$ for the PE-structure and $700 \mathrm{~m} . \mathrm{s}^{-2}$ for the GPreinforced structure.

It is also interesting to investigate the evolution of the equivalent force applied by each impacting vehicle to the structure during the impact. This quantity is obtained using Newton's second law, by multiplying the acceleration by the mass of the impacting vehicle. This force is plotted $v s$. the penetration of the vehicle in Fig.8. It gives an estimate of the global deformability of each structure in dynamic conditions. The response is linear at first in both cases. The maximum force is reached for the PE-reinforced structure: it is $70 \%$ greater than that of the maximum force obtained with the GP-reinforced structure. The apparent dynamic stiffness is also greater for the PE-reinforced structure. This result is somewhat surprising since GP is stiffer than PE. This is certainly due to the intercellular bond failure which caused an apparent softening of the structure. This result is consistent with the fact that the GPreinforced structure exhibits an apparent plastic response for a displacement lying between $75 \mathrm{~mm}$ and $160 \mathrm{~mm}$, which is also likely due to the intercellular bond failure. For the PE-reinforced structure, the impact force propagates more easily into the bulk of the whole reinforcement because of the lower number of failures, thus explaining the higher resistance against vehicle penetration. 


\subsection{Conclusion}

Impact tests performed on two different models of reinforced structures are

described in this section. Observing the videos obtained with two high-speed cameras enabled us to describe complex phenomena that occurred during the very short time period of the impacts while dismantling the structures after the tests provided useful information on the spatial distribution of the deformation in the bulk of the layers. The objective now is to propose a numerical model that mimics these experiments in order to assess how certain parameters influence the mechanical response of such structures and to complete the experimental observations. This model, after validation, is expected to pave the way for designing real reinforced structures to resist impact loading.

\section{NUMERICAL APPROACH}

From the observations and characteristics of the small scale impact, numerical models were built using a 2-dimensional Discrete Element Method and particular molecular dynamics (Cundall and Strack, 1979). The behaviour of the reinforced embankment during impact was reproduced qualitatively. The mechanisms involved were observed and compared with those obtained in the experiment. The aim of this part is first to propose a simple model in view to determining the parameters necessary to reproduce the response of the reinforced wall.

The reinforced wall was modelled under 2-dimensional conditions by a vertical cross section starting from the front of the wall and ending at the back of the wall, and including the point of impact between the vehicle and the reinforced wall. In this model, the back of the wall was modelled by a perfectly rigid wall condition. The wall itself was modelled by 19 superimposed layers of geocells filled with a soil material.

\subsection{Fill material modelling}


Different materials were modelled by particles whose diameters ranged from 2

$\mathrm{mm}$ to $4 \mathrm{~mm}$. The fill material was placed in the cells using a radius expansion method. Particle density was set to $600 \mathrm{~kg} \cdot \mathrm{m}^{-3}$ and the final void ratio $e$ to a value of 0.33 so that an apparent density of $450 \mathrm{~kg} \cdot \mathrm{m}^{-3}$ was obtained for the particle assemblies. The experimental fill material was modelled by a homogenized sample of particles presenting a unique set of mechanical parameters. The rheological contact model included linear contact laws of stiffness $k_{n}=1.210^{6} \mathrm{~N} / \mathrm{m}$ in the normal direction and $k_{s}=610^{5} \mathrm{~N} / \mathrm{m}$ in the tangential direction. A Coulomb friction criterion of coefficient $\mu=1$ was used to bound the value of the tangential force. In addition, no cohesion was taken into account. A rolling resistance was also considered in the contact model so that the shear resistance of the samples could be increased. Biaxial tests were conducted on representative sample to get the macro-mechanical properties. A Young's modulus value of $E=0.5 \mathrm{MPa}$, a Poisson's ratio of $v=0.20$ and a friction angle of, $24^{\circ}$ were obtained. The difference between the friction angle of the numerical sample and experimental material is discussed in Section 3.8.

\subsection{Reinforcement material}

The modelled reinforcement corresponds to greaseproof paper (GP). It was modelled by a chain of particles of diameter $d_{g e o}$ of $1.5 \mathrm{~mm}$, i.e. smaller than the soil particles (Fig.9). Contacts between the chain particles were given an inter-particular cohesion to represent tensile resistance. The behaviour of the GP strips was modelled with an elastic-linear-fragile law. The stiffness and inter-particular cohesion (normal and tangential) were set to fit the elastic part of the response of the experimental strips of raw material. The contact friction coefficient of the chain particles was set to the same value as that of the soil particles.

One reinforcement strip crosses the vertical plane chosen for the model several times. Consequently, the physical continuity of the strip material could not be 
represented in this vertical cross section. Thus a dummy interaction law was considered between the opposite edges of one cell. This interaction was considered mostly to counter the discontinuity of the strips in the vertical plane and then maintain the global stability of the reinforced wall throughout the calculation. It can be written as follows:

$$
\begin{array}{ll}
F=k_{e q} \cdot d & \text { for } d>d_{0} \\
F=0 & \text { for } d<d_{0}
\end{array}
$$

where $d$ is the distance between the edges of one cell in the modelling plane, $d_{0}$ the initial distance between the edges and $k_{e q}$ the stiffness coefficient of the interaction law. Many deformation mechanisms can affect a filled cell, resulting in movements of the fill material and thus different solicitations within the strip. The reinforced wall was modelled here in 2 dimensions here but the mechanisms of deformation of the cells are 3-dimensional. Consequently, it was not possible to predict the deformation mechanisms of the cells from modelling. The choice was made to deduce the value of $k_{e q}$, from an expansion test in the horizontal plane on an assembly of 9 cells (Fig.10). The 8 peripheral cells were filled with fill material particles. In the centre cell, a single particle was installed and its radius was progressively increased. The force in the chain particles and the radius of the centre cell were computed in order to deduce the value of the stiffness $k_{e q}$ of the interaction law between the reinforcement particles. The parameters of the basic reinforcement model are provided in Table 1.

\subsection{Impacting vehicle}

Only the steel ram of the radio-controlled vehicle was modelled as a single cylinder of $5 \mathrm{~kg}, 5 \mathrm{~cm}$ in diameter and $18 \mathrm{~cm}$ in length. The horizontal impact speed was $10 \mathrm{~m} \cdot \mathrm{s}^{-1}$. The micromechanical parameters are specified in Table 2.

\subsection{Results}


The response of the model is mainly assessed in terms of velocity of the

impacting vehicle vs. time from the impact beginning on. The experimental curve of the velocity vs. time is plotted in Fig. 11 along with its counterpart obtained with the experimental model.

It clearly appears that the experimental velocity decreases more quickly than in the numerical model. In other words, the actual deceleration is greater than that predicted by the model. It means that in experimental test, the energy provided by the impact is dissipated more quickly than in the numerical model. It is also worth mentioning that a slope break occurs in the numerical curve at $19 \mathrm{~ms}$. The objective now is to take into account various refinements of this model and to observe whether these changes induce greater deceleration or not.

\subsection{Environment dissipation}

Many DEM users consider an environment dissipation translated by a parameter called $\alpha$ to take all these effects more globally into account. Using such a parameter is convenient, even though actual physical interpretation remains quite obscure in practice. In this case, the unbalanced force of each particle is multiplied by a coefficient lower than one, thus leading to a vanishing unbalanced force. This automatically increases the energy dissipation in the system. It is often recommended to choose a value of 0.3 for this parameter in the case of cyclic dynamics problems such as earthquakes (Itasca, 1999). This value can be lower for fast dynamics problems, as in the current case. Several simulations with various values for this parameter $(\alpha=2.5 \%, 5 \%, 10 \%$, $20 \%$ ) were carried out in order to observe its influence on the response of the model. The model used here is the basic model presented above, without any change other than introducing this parameter. The curves obtained are shown in Fig.12. 
It seems that $\alpha=5 \%$ leads to the best agreement between experimental and

numerical responses. This value has the same order of magnitude as that used in studies dealing with dynamics described in the literature (Deluzarche, 2006; Bourrier, 2010), for instance.

The strength of this approach is illustrated by this result which shows that taking a correct value for $\alpha$ enables obtaining a numerical model which provides results in agreement with the experimental results. The drawback, however, is that some phenomena are hidden behind this global parameter. Consequently, this makes it difficult to examine the influence of certain parameters that directly influence the response of the structure, thus restricting any further improvement.

The idea now is to perform simulations with $\alpha=0 \%$, but with changes compared to the basic model. The objective at this stage is not really to try to obtain a numerical response which is exactly the same as the experimental one, but mainly to examine in turn the influence of various parameters and to see whether they change the response of the reinforced structure in the right direction. The different parameters which are investigated in the following sections are the shape of the impacting vehicle, the presence of a top plate on the box containing the reinforced structure, the stiffness of the springs used to model the through-thickness response of the layers, confinement and rolling resistance.

\subsection{Enhanced impacting vehicle}

A more realistic shape of the impacting vehicle is now considered for the model of the ram, the wheels and their bonds. The modelled masses and gravity centre are equivalent to the experimental car. All particles are bonded as a clump structure. Compared to the preceding model, the idea here is to take into account the junction between the ram and chassis. This junction is in fact an inclined plate. Some 
preliminary numerical simulations which are not detailed here have shown that the friction coefficient between soil and plate do not really influence the response, so adjusting the value of this parameter is not really an issue. In the numerical model used here, energy dissipation is due to the friction occurring between particles. Other sources of energy dissipation like particle crushing are not considered here. The curve obtained with the numerical model is shown in Fig.13 along with the experimental one.

The curve obtained in this case is similar to that of the basic model from 0 to 8 ms. From $8 \mathrm{~ms}$ on, a first break in the curve appears and the velocity decreases faster, so this goes in the right direction. At about $19 \mathrm{~ms}$, another break in the curve is observed and the velocity decreases less quickly. Comparing this curve with the deformed model vs. time shows that the first break in the slope (at $8 \mathrm{~ms}$ ) corresponds to the contact between the ram-chassis junction and the reinforced structure (Fig.13, right). The surface which causes internal friction within the soil is suddenly almost doubled, so the penetration resistance increases accordingly.

\subsection{Enhanced reinforcement model}

\subsubsection{Influence of the top plate}

In the model described in section 2 , it is explained that a plate was placed at the top of the frame in order to improve the rigidity of boundary conditions. One may wonder whether this plate hinders the vertical movement of the Coulomb wedge and if this affects the velocity curve. A horizontal plate was therefore added at the top of the impacted structure and a simulation was carried out with this model. This plate was modelled by a series of grains and springs, their equivalent mechanical properties being those of a steel plate with the stiffness of the real one. The curve obtained in this case is shown in Fig.14. 

basic model but it keeps decreasing up to about $35 \mathrm{~ms}$. Consequently the break in slope observed with the basic model at about $19 \mathrm{~ms}$ is caused by the movement of the Coulomb wedge. Before $19 \mathrm{~ms}$, the weight of this wedge contributes to the deceleration

\subsubsection{Enhanced reinforcement}

There are two main solutions to increase the resistance opposed to the lifting of the Coulomb wedge due to the impact. The first consists in increasing the density of the particles and therefore the mass of the corner. However, since this parameter was fixed during the experiments, this solution could not be considered. The second solution consists in adding a vertical reaction to the reinforcement in the direction opposite to the displacement of the layers. An additional load was then considered to take into account the anchor effect of each layer that could obviously not be modelled in 2 dimensions. This solution is investigated here.

As shown in section 2, the reinforced layers located above the impact level were seen to rise as the impact occurred. This rise was greater in the centre cross-section, i.e. close to the impact point, and progressively decreased towards left and right boundaries until a total vanishing at the lateral edges (Fig.15).

Tension in the strips appeared due to the deformation resulting from the relative displacement between the anchoring zones and central zone. The model was thus enhanced by adding in each layer a vertical effort in the opposite direction of the 
vertical displacement of the layer $d_{y}$, i.e. downward as the layers were lifted upwards during impact. The additional force was modelled by the action of linear springs (Fig.15) located on each side of the central zone and with an initial length $l_{i}$ and a stiffness $k_{i}$. For an upward displacement of a given layer, the restoring force $F_{V i}$ can be written as follow:

$$
F_{V i}=2 \cdot \sin \left(\arctan \left(\frac{d_{y}}{l_{i}}\right) \cdot k_{i} \cdot\left(\sqrt{l_{i}^{2}+d_{y}^{2}}-l_{i}\right)\right)
$$

The objective of adding the interaction law was to evaluate its influence on the accuracy and on the improvement of the basic model. Consequently, the initial lengths $l_{i}$ of the interaction springs were deduced from the image analysis of the experimental results.

The spring stiffness $k_{i}$ was deduced from extension tests modelled by the reinforced layer in the horizontal plane. The stiffness depends on the length of the layer tested, so that for a given vertical displacement of one layer during impact, the longer the spring, the greater the interaction force.

The maximal vertical force $F_{V \max }$ corresponds to the lowest lifted alveolar layer with an equivalent spring of stiffness $k_{1}=20.10^{3} \mathrm{~N} \cdot \mathrm{m}^{-1}$ and initial length $l_{1}=8 \mathrm{~cm}$ (hard case). The minimal vertical effort $F_{V \min }$ corresponds to the highest lifted alveolar layer with an equivalent spring of stiffness $k_{11}=5.10^{3} \mathrm{~N} \cdot \mathrm{m}^{-1}$ and initial length $l_{11}=23 \mathrm{~cm}$ (soft case).

Vertical restoring springs were added in the reinforcement model. All the restoring springs were given the same stiffness value: $k_{1}$ for the hard case and $k_{11}$ for the soft case. The results obtained are shown in Fig.16.

In both cases, the difference with the basic model is small in terms of vehicle velocity vs. time. A close inspection of the images obtained from the simulation shows, however, that the vertical displacement of the alveolar layers is strongly influenced by 
the stiffness of these springs. The fill material escaped from the alveoli in the case of stiff springs. This phenomenon is illustrated in Fig.17, where the dotted line represents the upper layer for both the stiff and the soft springs. In conclusion, it seems logical that the penetration resistance due to the Coulomb wedge remains the same as that obtained for the basic model.

\subsection{Enhanced soil model}

Modelling of granular media as a set of cylindrical (2D) or spherical (3D) particles leads to high rotational mobility of particles (Iwashita et al., 1998; Jiang et al., 2005) resulting in a reduction of the possible values of the macroscopic friction angle. In our case, the friction angle of the fill material equal to $24^{\circ}$, instead $40^{\circ}$ in the experiments. Particle shape improvement (Salot et al., 2009; Szarf et al., 2011; Chevalier et al., 2012) and rolling resistance (Iwashita et al., 1998; Jiang et al,. 2005) can be used to offset this effect. In this study, the rolling resistance law developed by Jiang and al. (2005) was used. Only the general principles of the rolling resistance law are presented here. A more detailed description of this model can be found in the reference above.

Jiang's law consists in applying a moment $M$ to particles in the direction opposing that of the total relative rotation $\theta_{R}$ of the system considered, i.e. \{particleparticle $\}$ or $\{$ particle-wall $\}$. The law can thus be represented by the moment - rotation relation. Physically, Jiang's model is equivalent to considering that particles present a flat surface in the contact zone (Fig.18). The width of the flat surface depends on the shape parameter $\delta$, which is the only parameter of the law. The moment $M$ can thus be deduced from the dummy geometry of the contact using total relative rotation $\delta$. The threshold values $M_{0}$ and $\theta_{R 0}$ depend on the contact properties and forces and their expressions are defined as follows (Jiang et al., 2005): 


$$
\begin{aligned}
& \theta_{R 0}=\frac{2 F_{n}}{k_{n} r \delta} \\
& M_{0}=\frac{1}{6} F_{n} r \delta
\end{aligned}
$$

where $k_{n}$ the normal contact stiffness, $F_{n}$ the normal component of contact force, $\delta$ the shape parameter.

The case where $\delta=0$ corresponds to the free rolling particles and the case where $\delta \rightarrow \infty$ to blocked rotations.

The values of the shape parameter $\delta$ and the corresponding macroscopic friction angle are summarized in Table 3. Young's modulus and Poisson's ratio were not modified by the shape parameter $\delta$.

Soils with different macro-mechanical friction angles were modelled to estimate the influence of this parameter on the mechanical response. The macro-mechanical friction angle was increased using the rolling resistance law. The other parameters characterizing the model remain the same as those chosen for the basic simulation (R1 and I1). The corresponding curves are shown in Fig.19.

Strong influence of the friction angle can be observed. The greater the friction angle, the greater the deceleration, which is here the objective: to reflect the experimental response. It is also noteworthy that the break in the slope at $19 \mathrm{~ms}$ is still visible in all cases. It must however be pointed out that a computation time approximately 4 times greater than that needed for the basic simulation was required to perform each of these simulations.

\subsection{Conclusion}


In conclusion of the simulations presented above, it can be said that the shape of

the ram-chassis, the upper plate placed on the model and the friction angle have a significant influence on the velocity curve vs. time, whereas the confinement and rigidity of the springs modelling the link between the layers have almost no influence. The objective now is to combine all these effects to try to obtain a numerical response that better matches the velocity curve of the experimental response.

\section{CONCLUSION}

This paper presents study of the effect of impacts on a soil wall reinforced with geocells based on experimental and numerical results.

Two impact experiments at a one-tenth scale were carried out on geocell structures. Two materials with very different mechanical properties were chosen for the alveolar reinforcement: paper (stiff-fragile mechanical response) and polymer (significant strain at failure). The mechanical properties of these materials were characterized with tensile tests. The fill material was a mixture of expanded clay beads and polystyrene micro-beads. Glycerine was added to this mixture to avoid segregation during mixing. The size and the density of this model fill material match the experimental fill material well. These experiments provided better understanding of geocell wall behaviour during impact and the parameters that influence this behaviour. Based on these experiments a numerical model using a 2-dimensional discrete method and particular molecular dynamics was proposed. This numerical model gives results which are similar to those provided by the paper experiment model. A vertical cross-section of the wall was modelled starting at the front of the wall and ending at its rear. A basic reinforcement model was built and then progressively modified to improve the initial model. These improvements dealt with: (1) introducing a pull-back force on each layer, representing the influence of the missing dimensions of the model, (2) 
changing the shape of the impacting vehicle and, (3) increasing the shear strength of the fill material.

Although a difference between numerical and experimental results could be observed, it was possible to predict qualitatively the global kinematics response of the wall. The different improvement approaches showed that the main difficulty was to obtain a sufficient level of energy dissipation in the model, especially in the 2dimensional discrete model involving spherically shaped particles. Increasing the shear strength of the fill material narrowed the difference between the experimental and numerical results. It would also be interesting to address the problem of particle crushing in further work because it certainly influences the mechanical behaviour. The effect of broadly used local damping in the model showed that it is possible to obtain good results as soon as the local damping value is well chosen. The dissipation of energy in the numerical modelling is not as important in the experimental test, revealing that some mechanisms still remain unclear and then not reproduced by the model. The local damping can be used to counterbalance this difference, as long as its influence on the modelling results is clearly known. In addition, the value of local damping coefficient should be taken as low as possible since its physical significance is difficult to explain, especially in dynamic testing.

Now that important parameters were identified, future work will focus on refining the numerical analysis by modelling a wall in three dimensions and then moving on to full-scale experiments. 


\section{REFERENCES}

Bertrand, D., Nicot, F., Gotteland, Ph., Lambert, S., 2005. Modelling a geocomposite cell using discrete analysis. Computers and Geotechnics. 32(8), 564-577. Bourrier, F., Nicot, F., Eckert, N., Darve, F., 2010. Comparing numerical and experimental approaches for the stochastic modeling of the bouncing of a boulder on a coarse soil. European Journal of Environmental and Civil Engineering. 14(1), 87-111.

Bourrier, F., Lambert, S., Heymann, A., Gotteland, P., Nicot, F., 2011. How multi-scale approaches can benefit the design of cellular rockfall protection structures Canadian Geotechnical Journal, 48(12), 1803-1816.

Chen, R.-H., Huang, Y.-W., Huang, F.-C., 2013. Confinement effect of geocells on sand samples under compression. Geotextiles and Geomembranes. 37, 35-44.

Chevalier, B., Combe, G., Villard, P., 2012. Experimental and discrete element modeling studies of the trapdoor problem: influence of the macro-mechanical frictional parameters. Acta Geotechnica. 7, 15-39.

Chew, S.H., Tan, S.A., Karunratne, G.P., Chiew Chiat, N.G., 2003. Performance of geosynthetic reinforced soil wall subject to blast loading: Experimental and numerical study, in: Ling H.I., Leshchinsky D., Tatsuoka F. (Eds), Reinforced soil Engineering: Advances in research and practice. CRC Press, Boca Raton, pp. 363-393. Cundall, P.A., Strack, O.D.L., 1979. A discrete numerical model for granular assemblies. Geotechnique. 29, 47-65.

Deluzarche, R., Cambou, B., 2006. Discrete numerical modeling of rockfill dams. International Journal for Numerical and Analytical Methods in Geomechanics. 30(11), 1075-1096.

Eurocode 1, 1991. Actions on structures - Part 1-7: Accidental actions from impact and explosions. 
Eurocode 8, 2005. Eurocode 8: Design of structures for earthquake resistance -

Part 5: Foundations, retaining structures and geotechnical aspects, pp. 32-35.

Huang, C.C., Horng, J.C., Chang, W.J., Chiou, J.S., Chen, C.H., 2011. Dynamic behavior of reinforced walls - Horizontal displacement response. Geotextiles and Geomembranes. 29, 257-267.

Itasca, 1999. PFC2D, Theory and background. Itasca Eds.

Iwashita, K., Oda, M., 1998. Rotational resistance at contacts in simulation of shear band development by DEM. Journal of Engineering Mechanics. 124(3), 285-292. Jiang, M.J., Yu, H.S., Harris, D., 2005. A novel discrete model for granular material incorporating rolling resistance. Computers and Geotechnics. 32(5), 340-357. Koseki, J., 2012. Use of geosynthetics to improve seismic performance of earth structures. Geotextiles and Geomembranes. 34. 51-68.

Lambert, S., Gotteland, P., Nicot, F., 2009. Experimental study of the impact response of geocells as components of rockfall protection embankments. Natural Hazards and Earth System Sciences. 9, 459-467.

Lee, K.Z.Z., Chang, N.Y., Ko, H.Y., 2010. Numerical simulation of geosynthetic-reinforced soil walls under seismic shaking. Geotextiles and Geomembranes. 28, 317-334.

Leshchinsky, D., Ling, H.I., Wang, J.P., Rosen, A., Mohri, Y., 2009. Equivalent seismic coefficient in geocell retention systems. Geotextiles and Geomembranes. 27(1), 9-18.

Ling, H., Leshchinsky, D., Wang, J., Mohri, Y., Rosen, A., (2009). Seismic Response of Geocell Retaining Walls: Experimental Studies. Journal of Geotechnical and Geoenvironmental Engineering. 135(4), 515-524. 
loading responses of foundations on geocell-reinforced sand. Geotextiles and

603 Geomembranes. 32, 55-68. earthquakes, in: Proceeding of the World Engineering Congress, Vol.9, Tokyo (Japan), pp.176-182.

Nomura, T., Inoue, S., Fuchigami, M., Yokota, Y., Kubo, T., Tatta, N., Arai, K.:

Experimental research of reinforced soil wall for rock-fall protection, in: 7th 2002.

Okabe, S., 1924. General theory on earth pressure and seismic stability of retaining walls and dams. Journal of the Japan Society of Civil Engineering. 10(6), $1277-1323$.

Parsons, R.L., Pokharel, S., Han, J., Halahmi, I., Leshchinsky, D., 2009.

Behavior of geocells-reinforced granular bases under static and repeated loading. In: Iskander, M., Laefer, D.F., Hussein, M.H. (Eds) Contemporary Topics in Ground Modification, Problem Soils and Geo-support, ASCE, 409-416.

Racana, N., Grédiac, M., Gourvès, R., 2003. Pull-out response of corrugated geotextile strips. Geotextiles and Geomembranes. 21(5), 265-288.

Salot, C., Gotteland, P., Villard, P., 2009. Influence of relative density on granular materials behavior: DEM simulations of triaxial tests. Granular Matter. 11(4), 221-236.

Saran, S., 2010. Reinforced soil and its engineering applications, Second edition, IK International Publishing. 

numerical study of the influence of grain shape on the mechanical behaviour of granular materials. Powder Technology. 208(2), 279-288.

628 Yang, X., Han, J., Pkharel, S.K., Manandhar, C., Parsons, R.L., Leshchinsky, D., 629 Halahmi, I., 2012. Accelerated pavement testing of unpaved roads with geocells630 reinforced sand bases. Geotextiles and Geomembranes. 32, 95-103. 
Fig.1 - Diagram of the experimental reinforced wall

Fig.2 - Results of tensile tests on single and bonded strips of GP and PE

Fig.3 - Views of the experimental site showing the location of the tested walls and the high-speed cameras

Fig. 4 - Vertical cross section diagrams of the wall showing the deformation after impact

Fig. 5 - Deformation of the front face of the PE wall for the layer located at impact level (top view)

Fig. 6 - Location of broken bonds for the GP wall, in the layer located at impact level Fig.7 - Penetration length and vehicle speed versus time for both the GP and the PE walls

Fig.8 - Acceleration and unbalanced force on impacting vehicle versus time for both the GP and the PE walls

Fig. 9 - Diagram showing the numerical model used for the reinforcement strips

Fig. 10 - Diagram showing the principle of the numerical expansion test on filled cells Fig. 11 - Comparison of vehicle velocity versus time for the experimental wall (GP) and basic numerical model

Fig. 12- Influence of the local damping coefficient used in the basic numerical model on the response of the wall in terms of vehicle velocity versus time

Fig. 13- Vehicle velocity versus time for the basic model, the enhanced vehicle model and the experimental test

Fig. 14 - Vehicle velocity versus time for the basic model, the top plate model and the experimental test

Fig. 15 - Enhanced model for the reinforcement strips

Fig. 16 - Vehicle velocity versus time for the experimental test, the basic numerical model and the improved reinforcement models (soft and hard cases)

Fig. 17 - Cross-section of the modelled wall in the case of the improved reinforcement model with soft stiffness (left) and hard-stiffness (right) springs. The dotted line represents the top boundary of the reinforcement strip during impact Fig.18 - Description of the rolling resistance model of Jiang et al. (2005) 
663 Fig. 19 -Effect of rolling resistance on the vehicle velocity versus time for the basic 664 case and for the rolling resistance case

665 
Table 1. Physical and micromechanical parameters of the reinforcement

\begin{tabular}{cccccc}
\hline $\begin{array}{c}\rho_{G E O} \\
{\left[\mathbf{k g} / \mathbf{m}^{3}\right]}\end{array}$ & $\begin{array}{c}\boldsymbol{r}_{G E O} \\
{[\mathbf{m m}]}\end{array}$ & $\begin{array}{c}\boldsymbol{k}_{n, G E O}=k_{s, G E O} \\
{[\mathbf{N} / \mathbf{m}]}\end{array}$ & $\begin{array}{c}n_{b, G E O}=s_{b, G E O} \\
{[\mathbf{N} / \mathbf{m}]}\end{array}$ & $\begin{array}{c}\boldsymbol{\mu}_{G E O} \\
{[-]}\end{array}$ & $\begin{array}{c}\boldsymbol{k}_{\text {eq }} \\
{[\mathbf{N} / \mathbf{m}]}\end{array}$ \\
\hline 300 & 0,75 & $3.3310^{8}$ & 45 & 1.0 & $310^{5}$ \\
\hline
\end{tabular}

667 
668 Table 3. Physical and micromechanical parameters of the impact loading

\begin{tabular}{cccccc}
\hline $\begin{array}{c}\rho_{I M P} \\
{\left[\mathbf{k g} / \mathbf{m}^{3}\right]}\end{array}$ & $\begin{array}{c}\boldsymbol{r}_{I M P} \\
{[\mathbf{m m}]}\end{array}$ & $\begin{array}{c}k_{n, I M P}=k_{s, I M P} \\
{[\mathbf{N} / \mathbf{m}]}\end{array}$ & $\begin{array}{c}\mu_{I M P} \\
{[-]}\end{array}$ & $\begin{array}{c}v_{I M P} \\
{\left[\mathbf{m} . \mathbf{s}^{-1}\right]}\end{array}$ & $\begin{array}{c}\boldsymbol{h}_{I M P} \\
{[\mathbf{c m}]}\end{array}$ \\
\hline $1,41.10^{4}$ & 25 & $10^{10}$ & 1,0 & 10 & 17,5 \\
\hline
\end{tabular}

669

670 
671 Table 1. Values of shape parameter and macroscopic friction angle

\begin{tabular}{ll}
$\delta$ & $\varphi_{S O L}\left[^{\circ}\right]$ \\
\hline 0 & 24 \\
\hline 0,2 & 26 \\
\hline 0,4 & 28 \\
\hline 0,6 & 31 \\
\hline 0,8 & 33 \\
\hline 1,0 & 35 \\
\hline 2,0 & 43,5 \\
\hline$\infty$ & 52 \\
\hline
\end{tabular}

672

673 


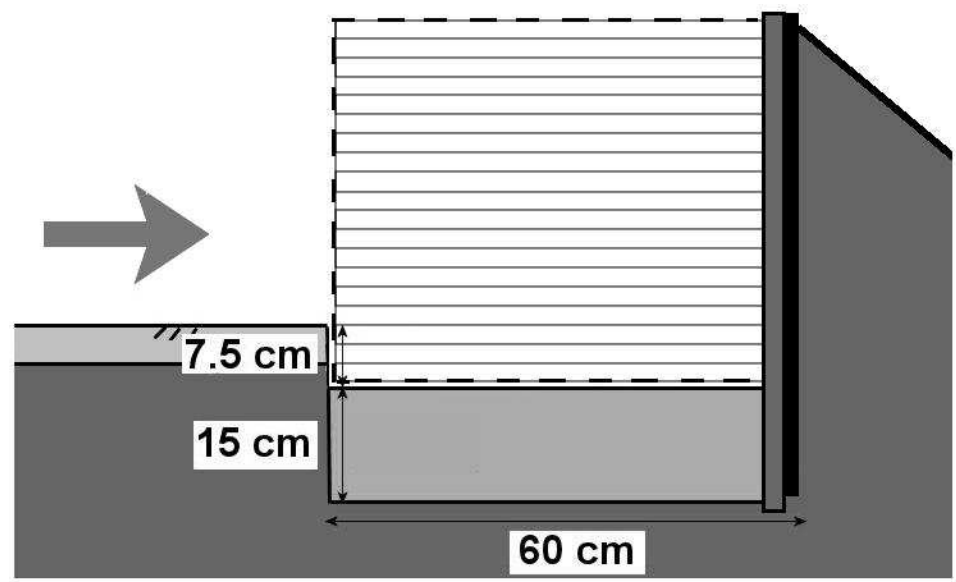

vertical cross section

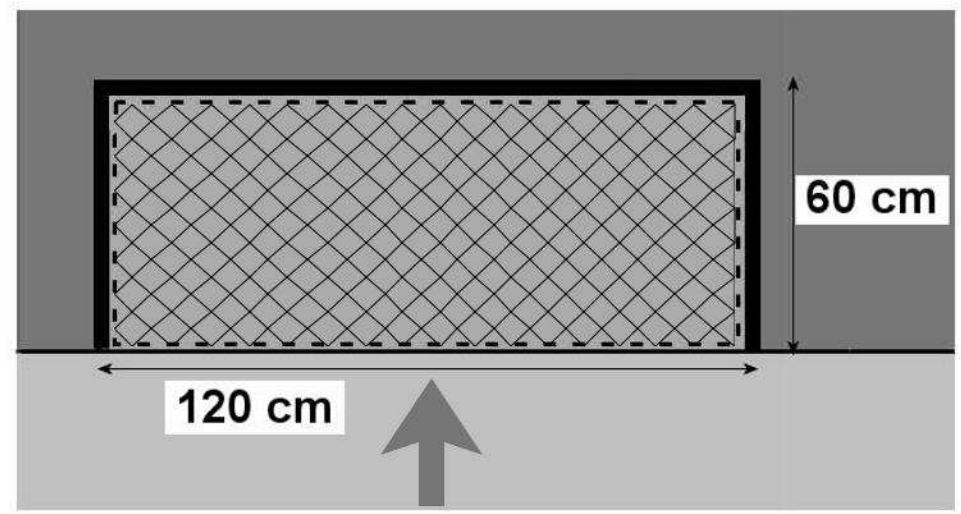

top view

\section{$\square$ tarmac road}

$\square$ compacted sand layer

i - - ' location of reinforced wall

on-site natural soil

- outer coffering wood

676

677 
Fig.2 - Results of tensile tests on single strips and bonded strips of GP and PE.
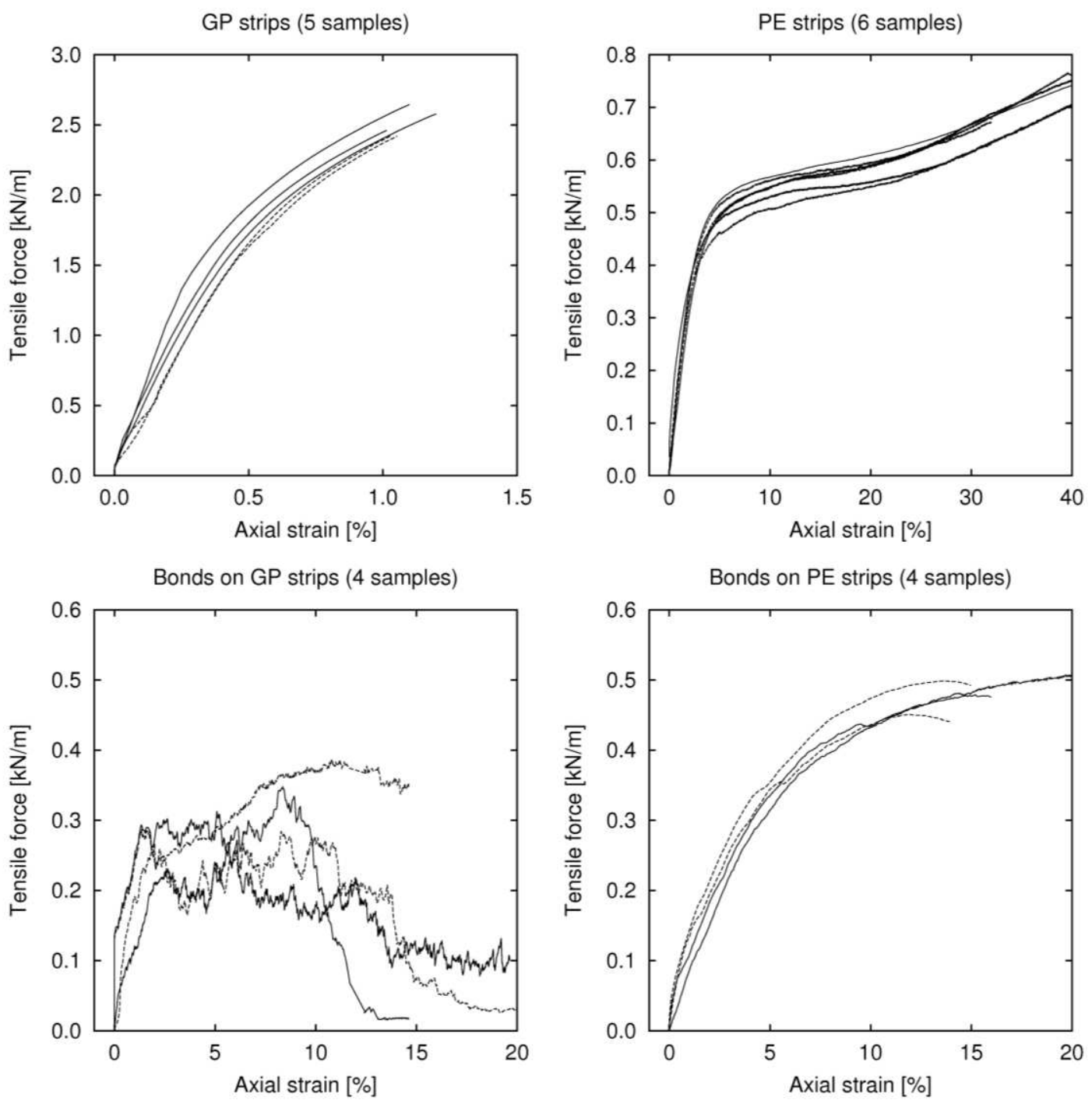
Fig.3 - Views of the experimental site showing the location of the tested walls and the high speed cameras

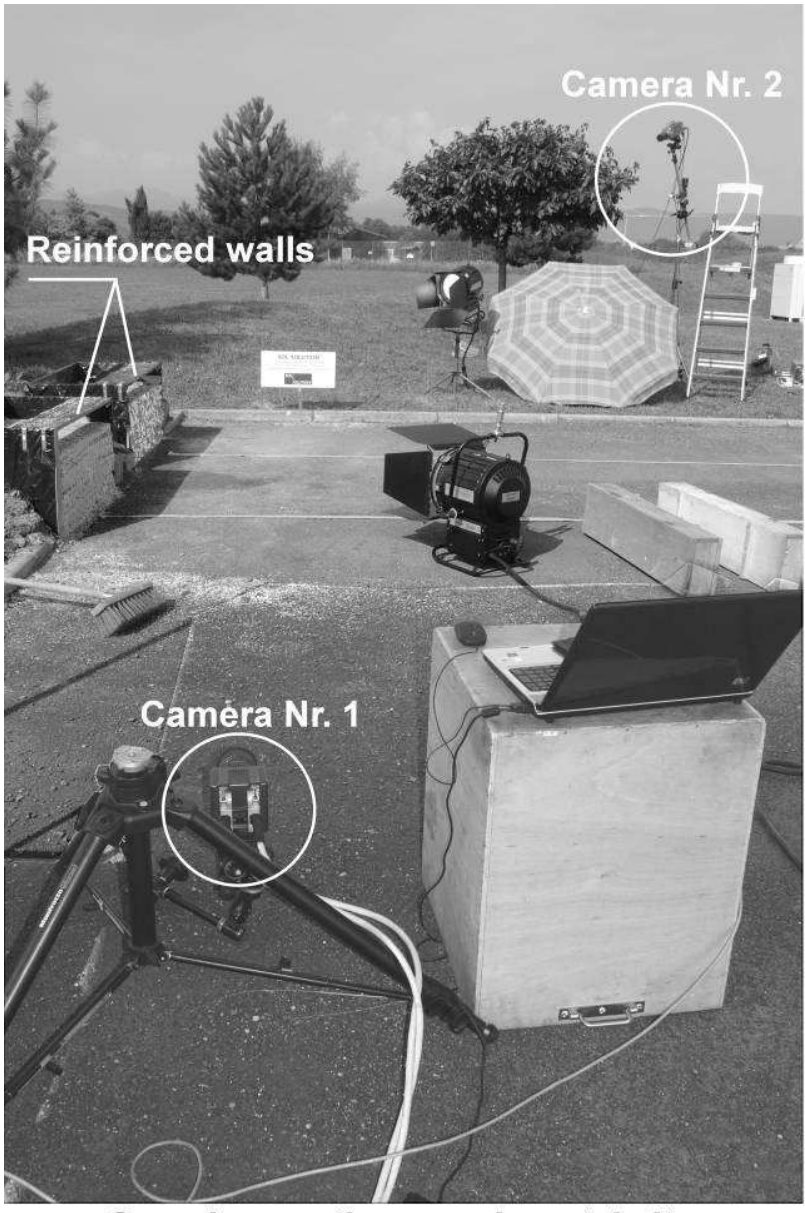

Overview on the experimental site

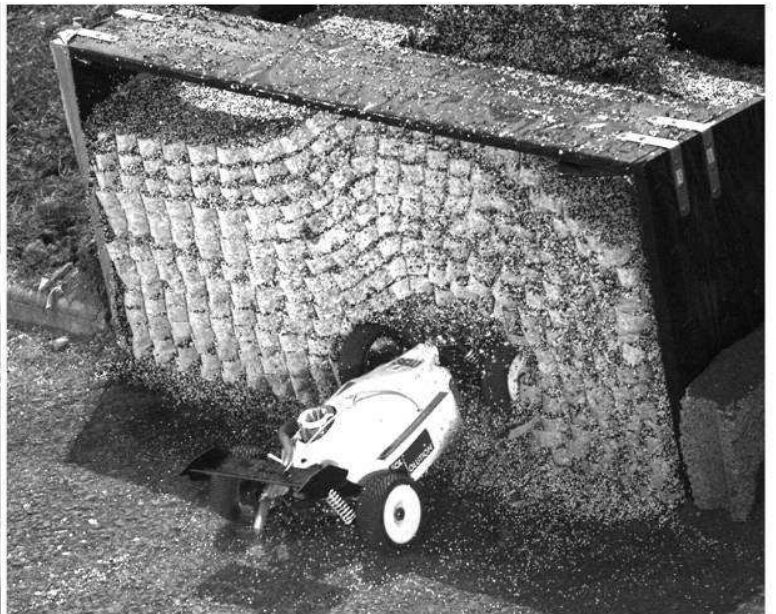

View from Camera Nr.2 during impact

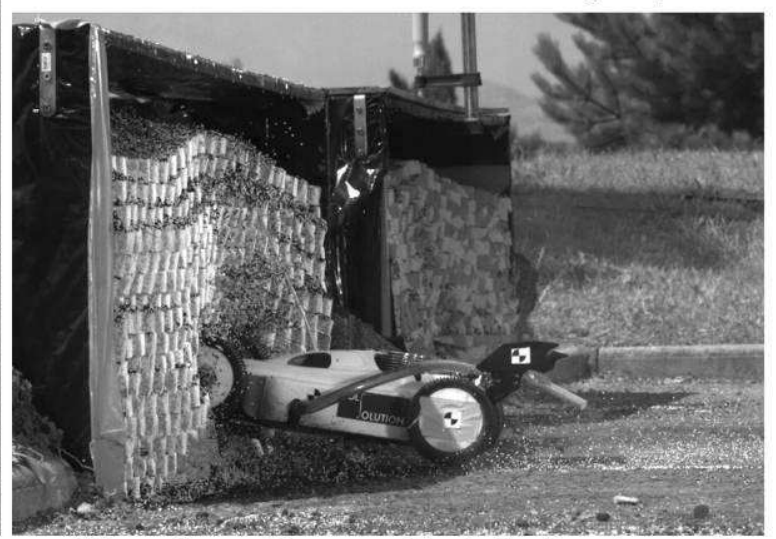

View from Camera Nr.1 during impact 
687 Fig. 4 - Vertical cross section diagrams of the wall showing the deformation after 688 impact

689

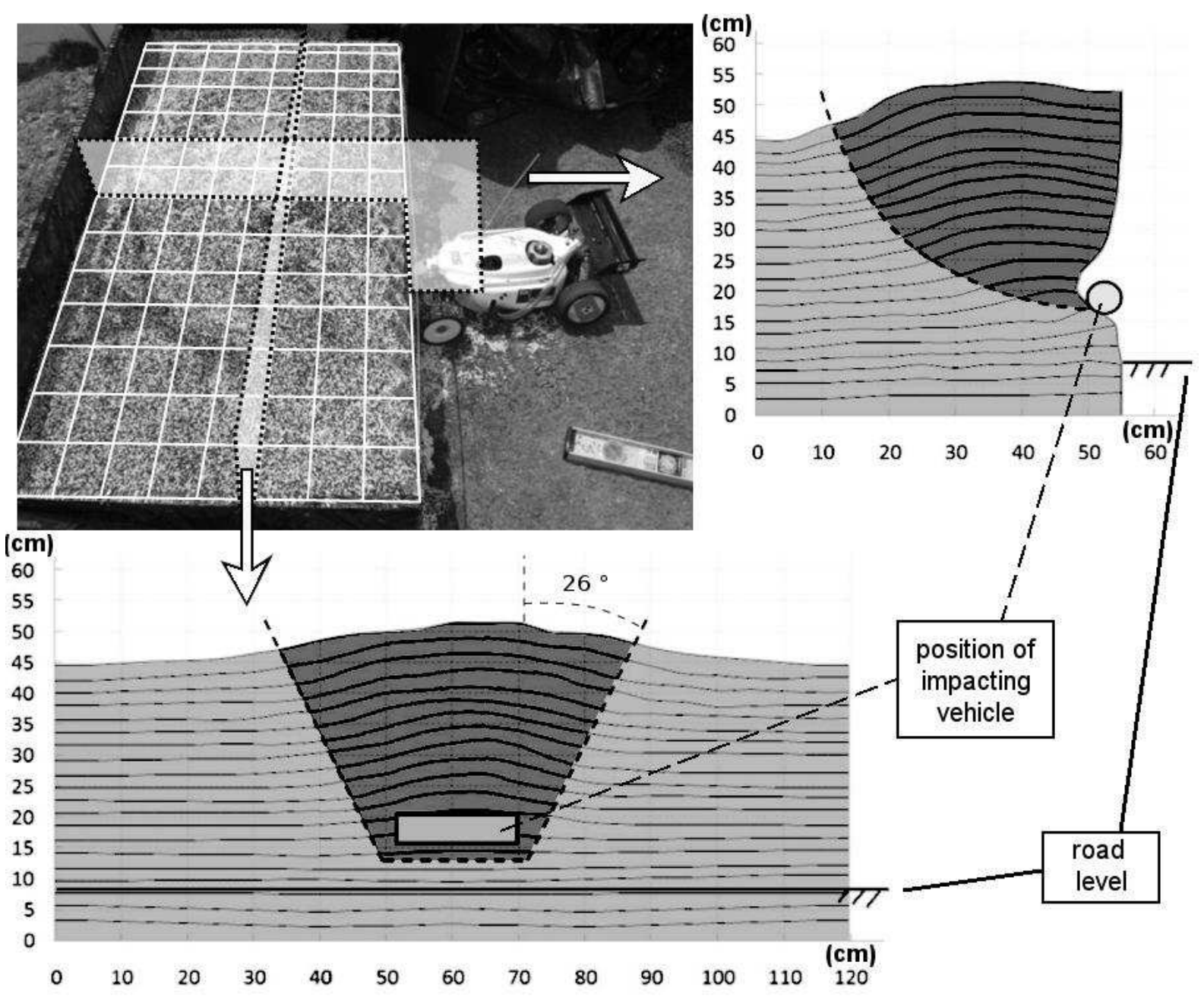


692 Fig. 5 - Deformation of the front face of the PE wall for the layer located at impact 693 level (top view)

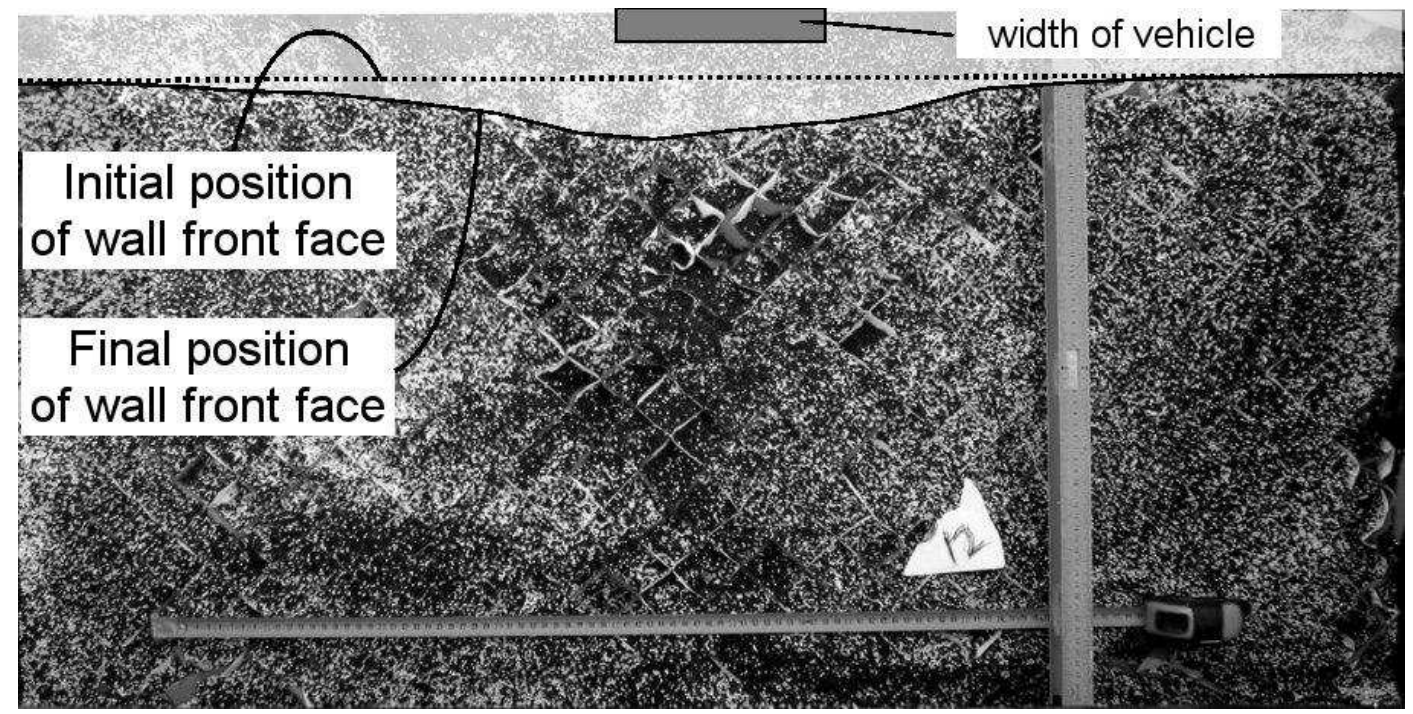

696

697 
698

699

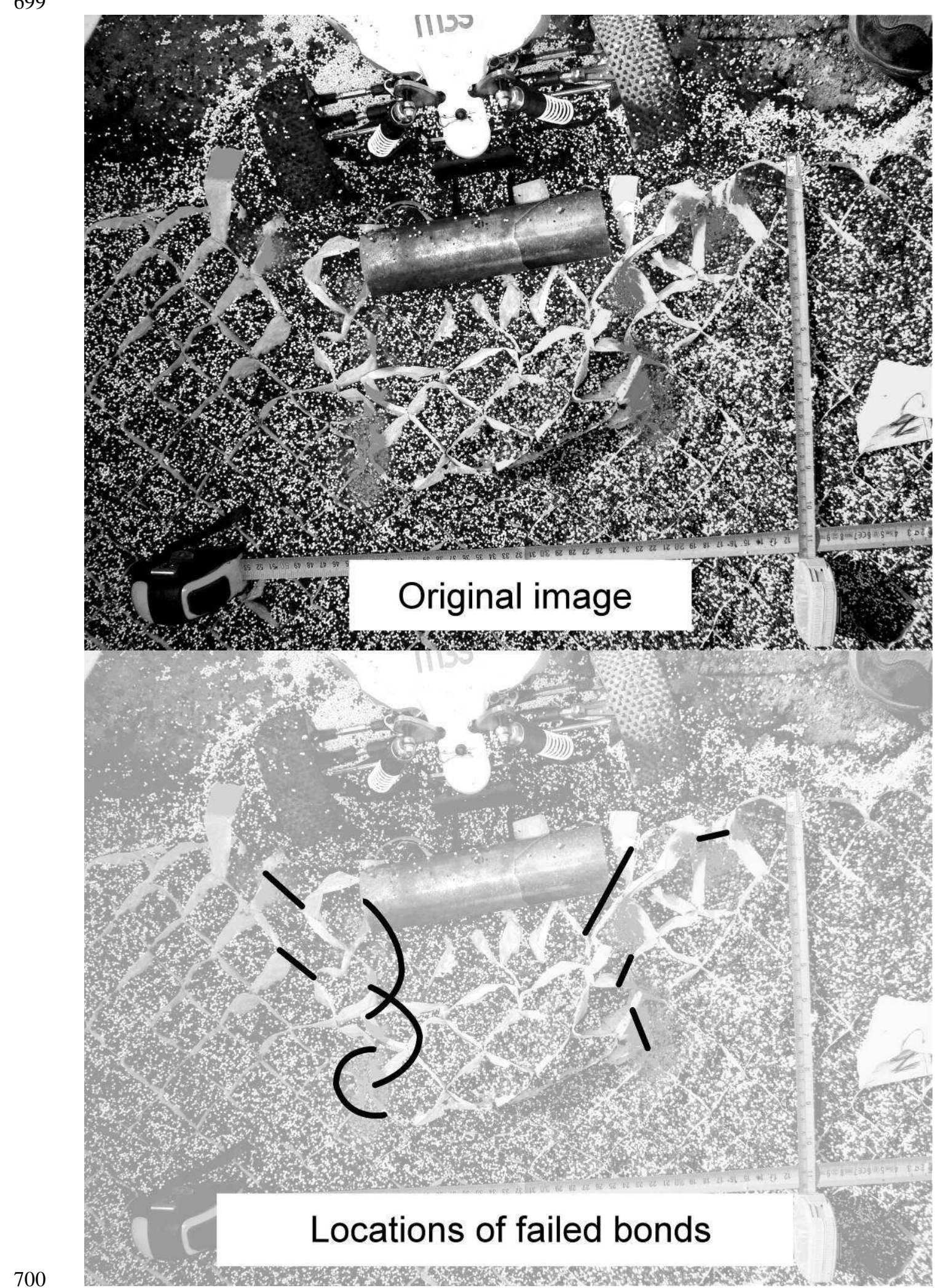

Fig. 6 - Location of broken bonds for the GP wall, in the layer located at impact level 
Fig.7 - Penetration length and vehicle speed versus time for both GP and PE walls
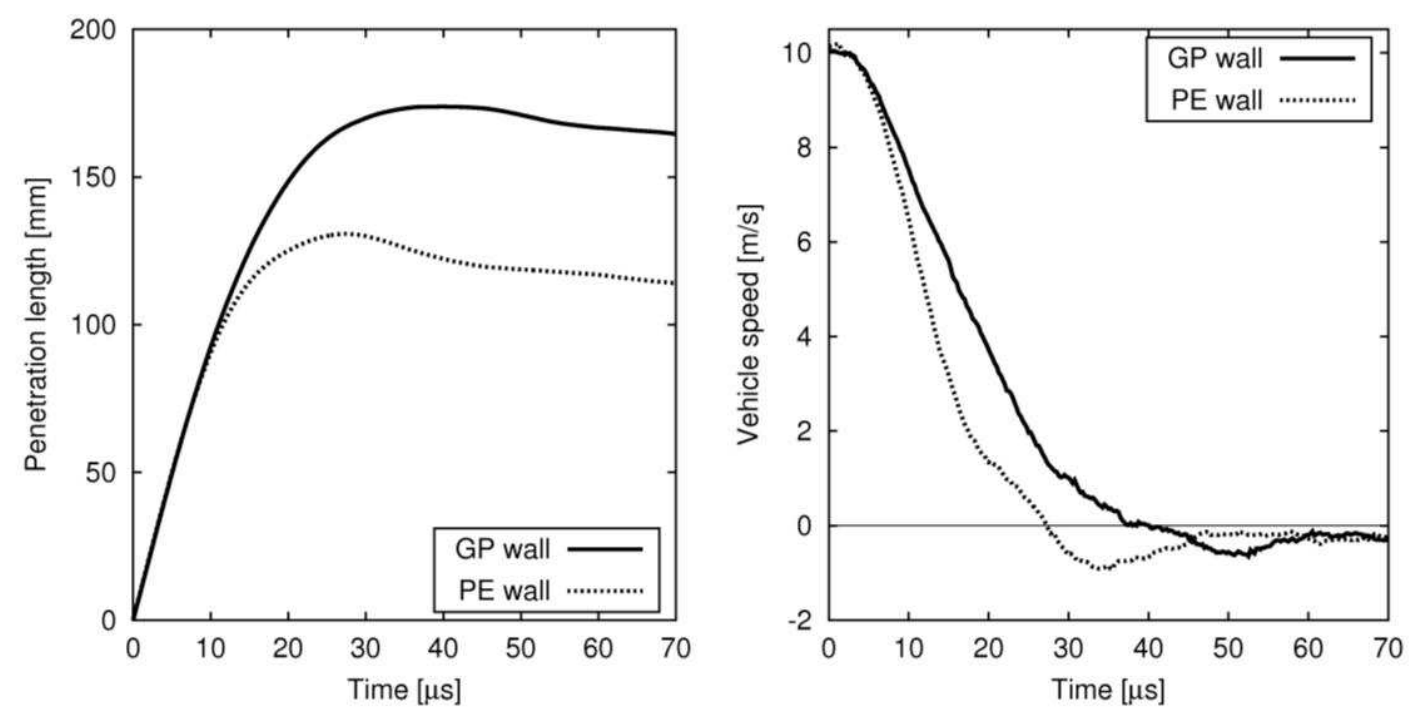
Fig.8 - Acceleration and unbalanced force on impacting vehicle versus time for both GP and PE walls

708
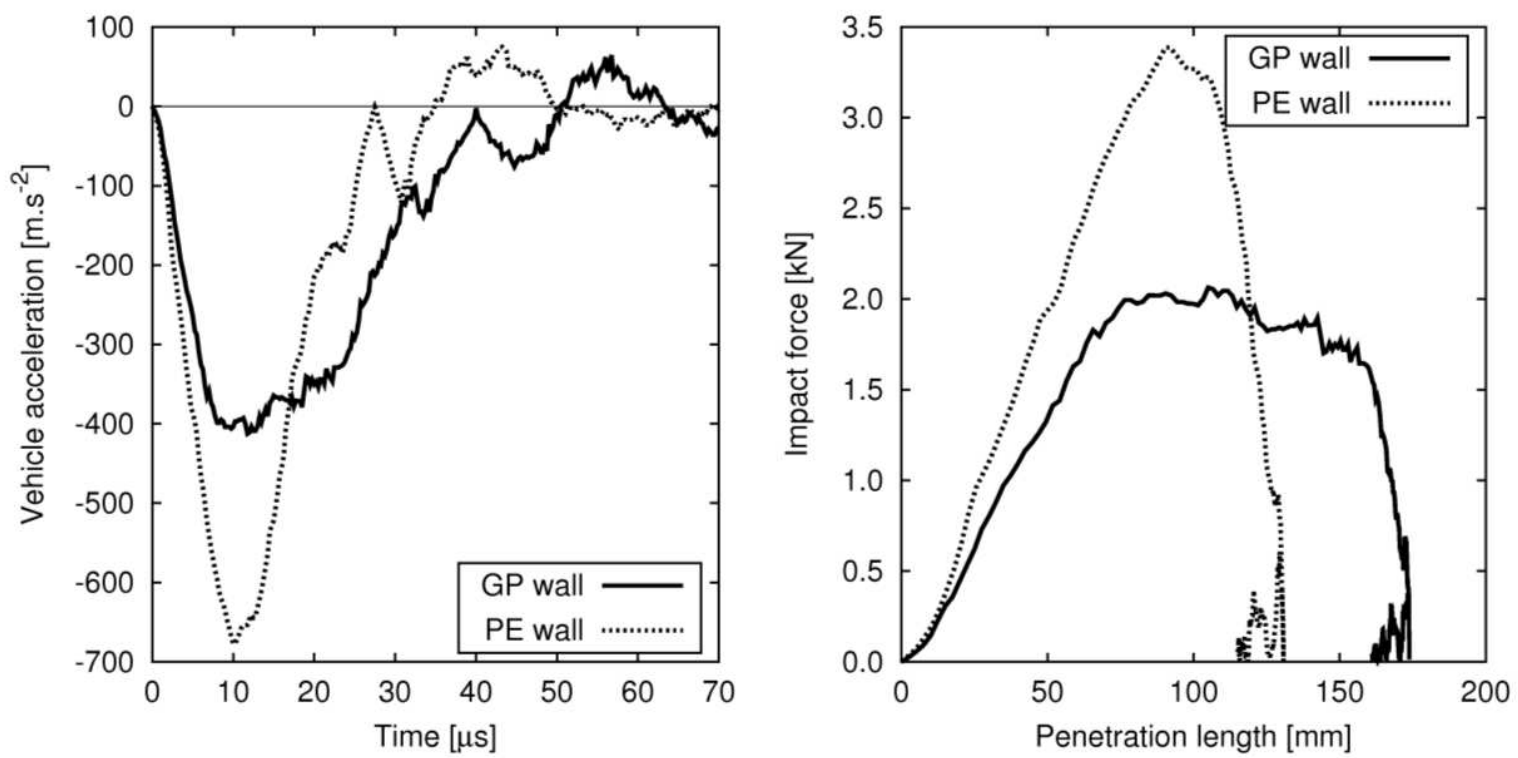

709 
711 712

713
Fig. 9 - Diagram showing the numerical model used for the reinforcement strips

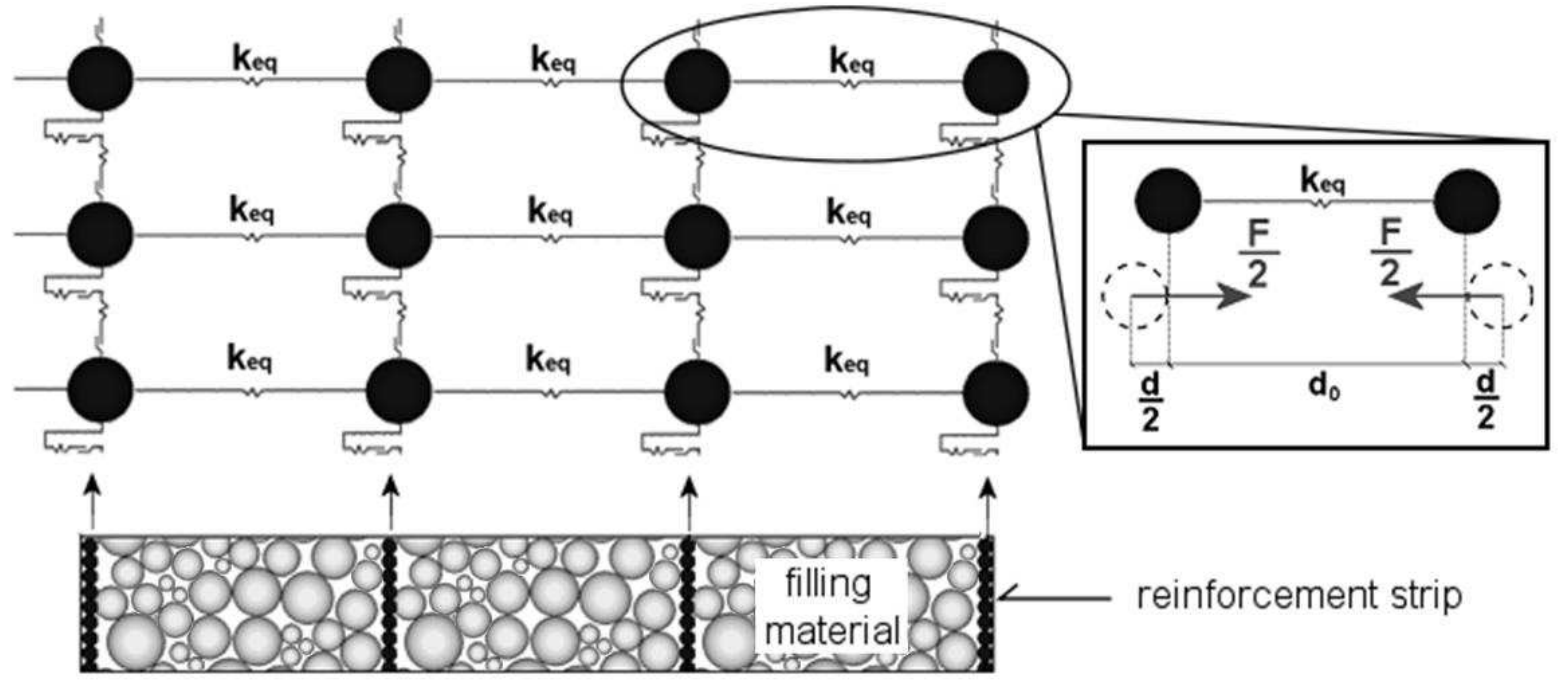


715 Fig. 10 - Diagram showing the principle of the numerical expansion test on filled cells

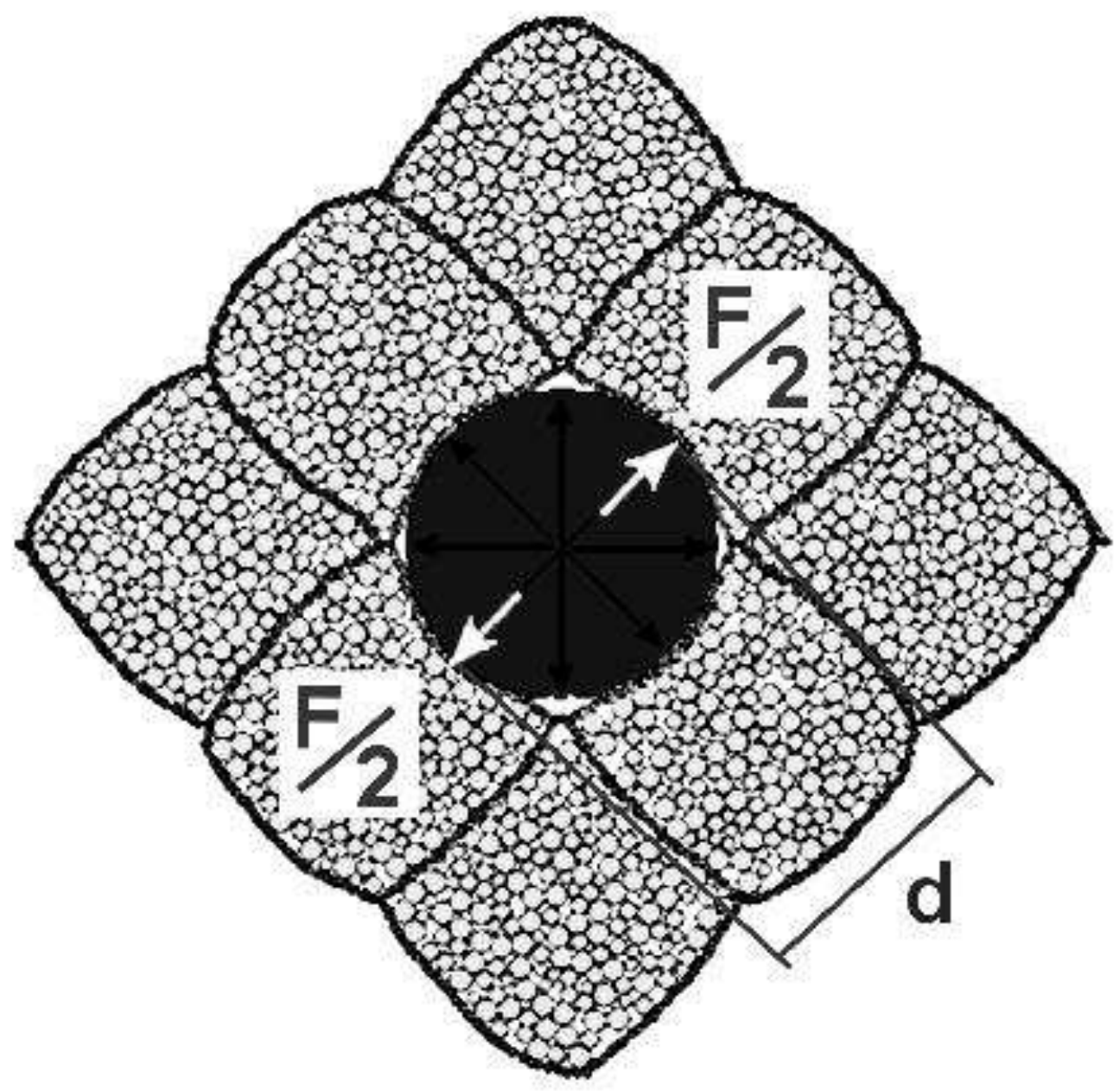


719 Fig. 11 - Comparison of vehicle velocity versus time for the experimental wall (GP) 720 and basic numerical model.

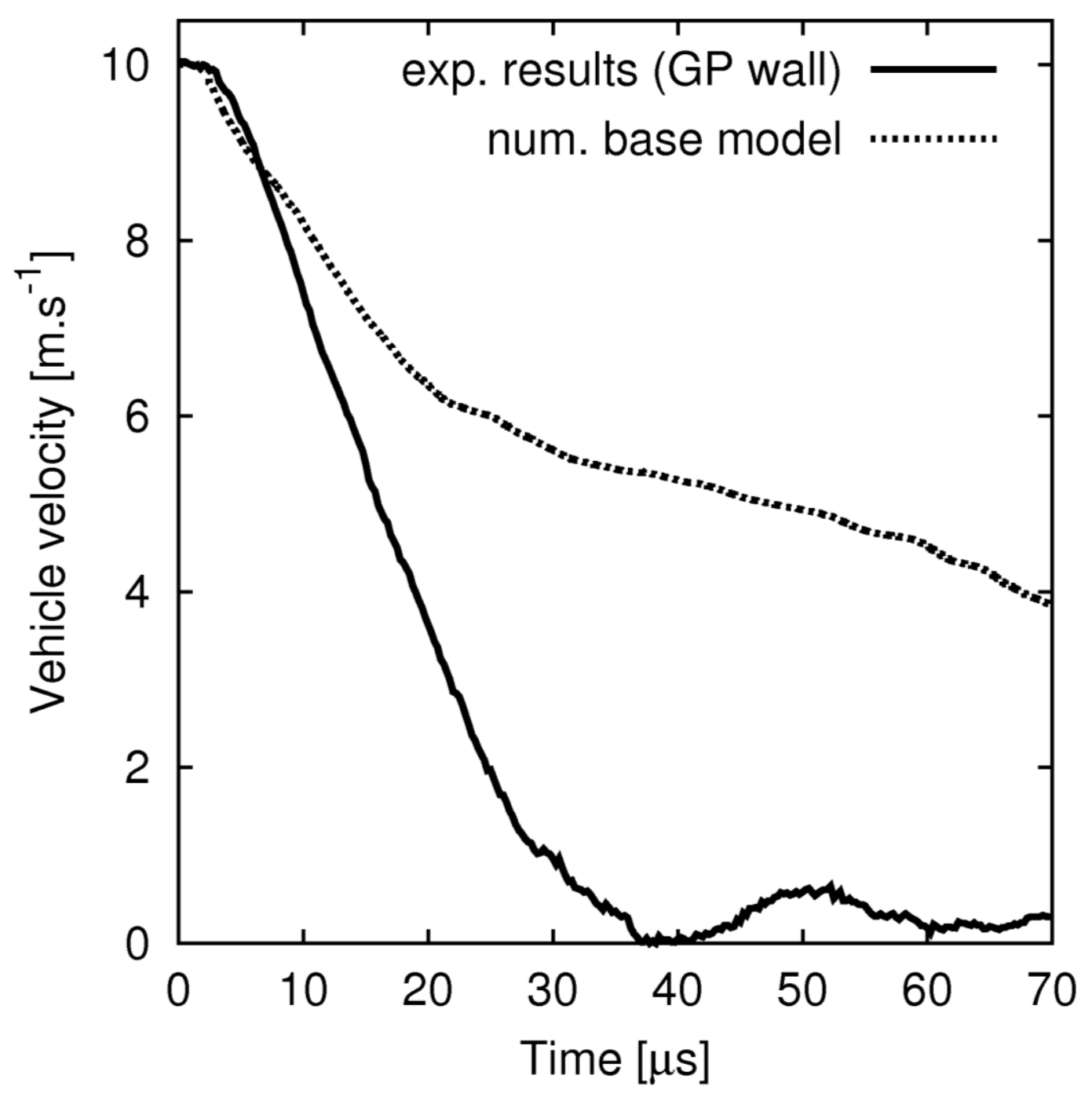


Fig. 12- Influence of the local damping coefficient in the basic numerical model on the response of the wall in terms of vehicle velocity versus time.

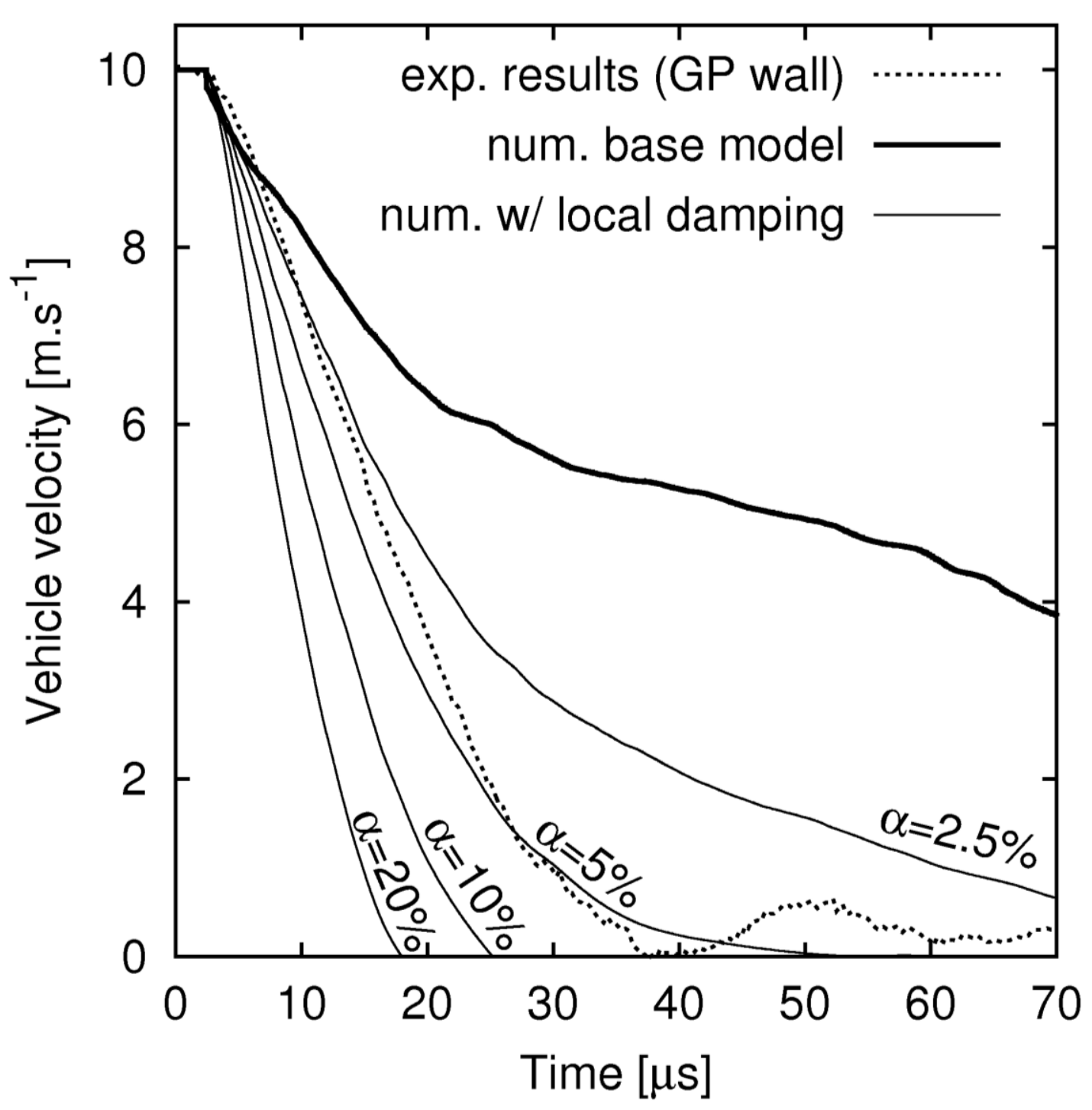


729 Fig. 13- Vehicle velocity versus time for the basic model, enhanced vehicle model and 730 experimental test.

731
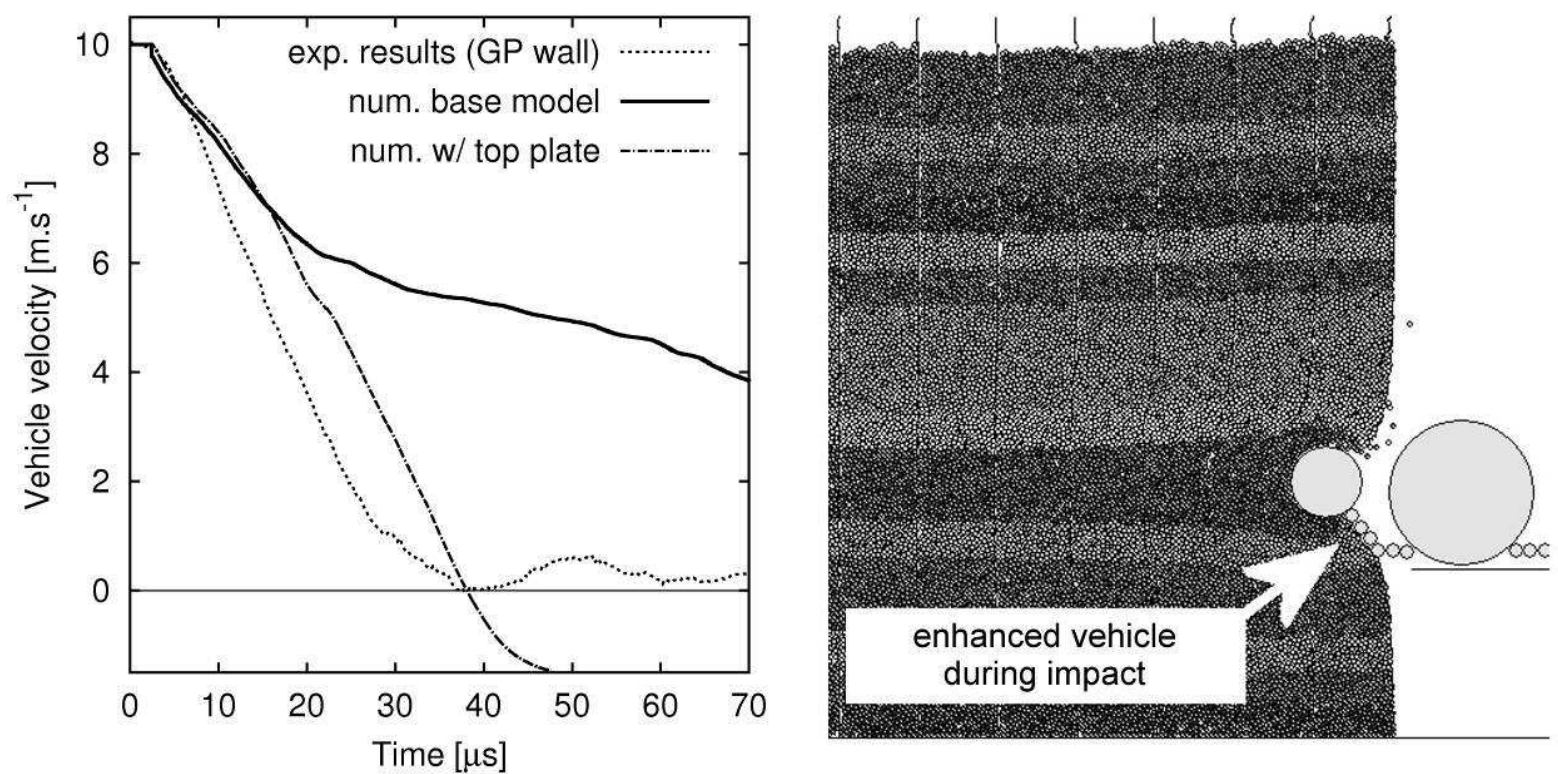
Fig. 14 - Vehicle velocity versus time for the basic model, top plate model and

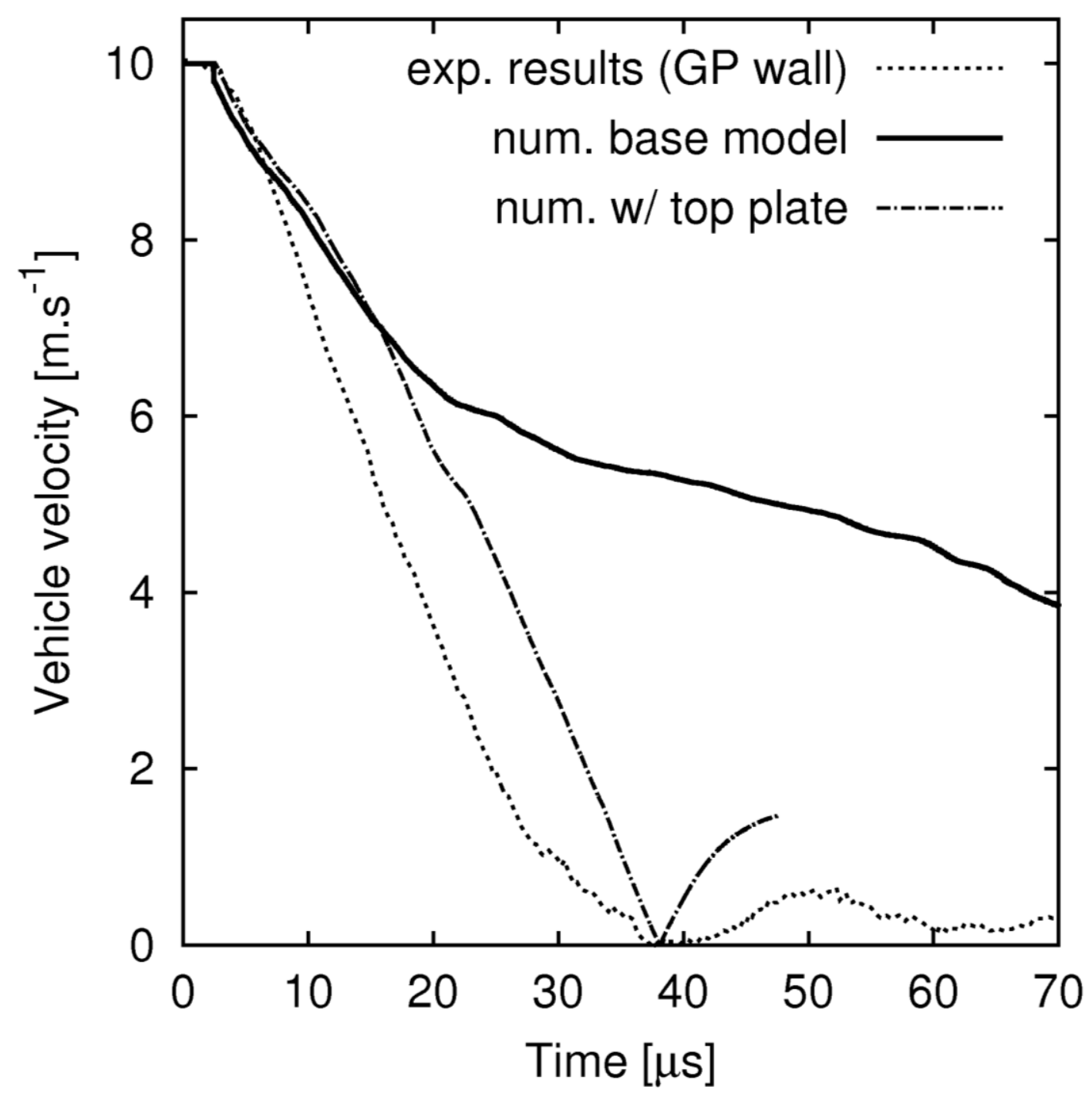


Fig. 15 - Enhanced model for the reinforcement strips.
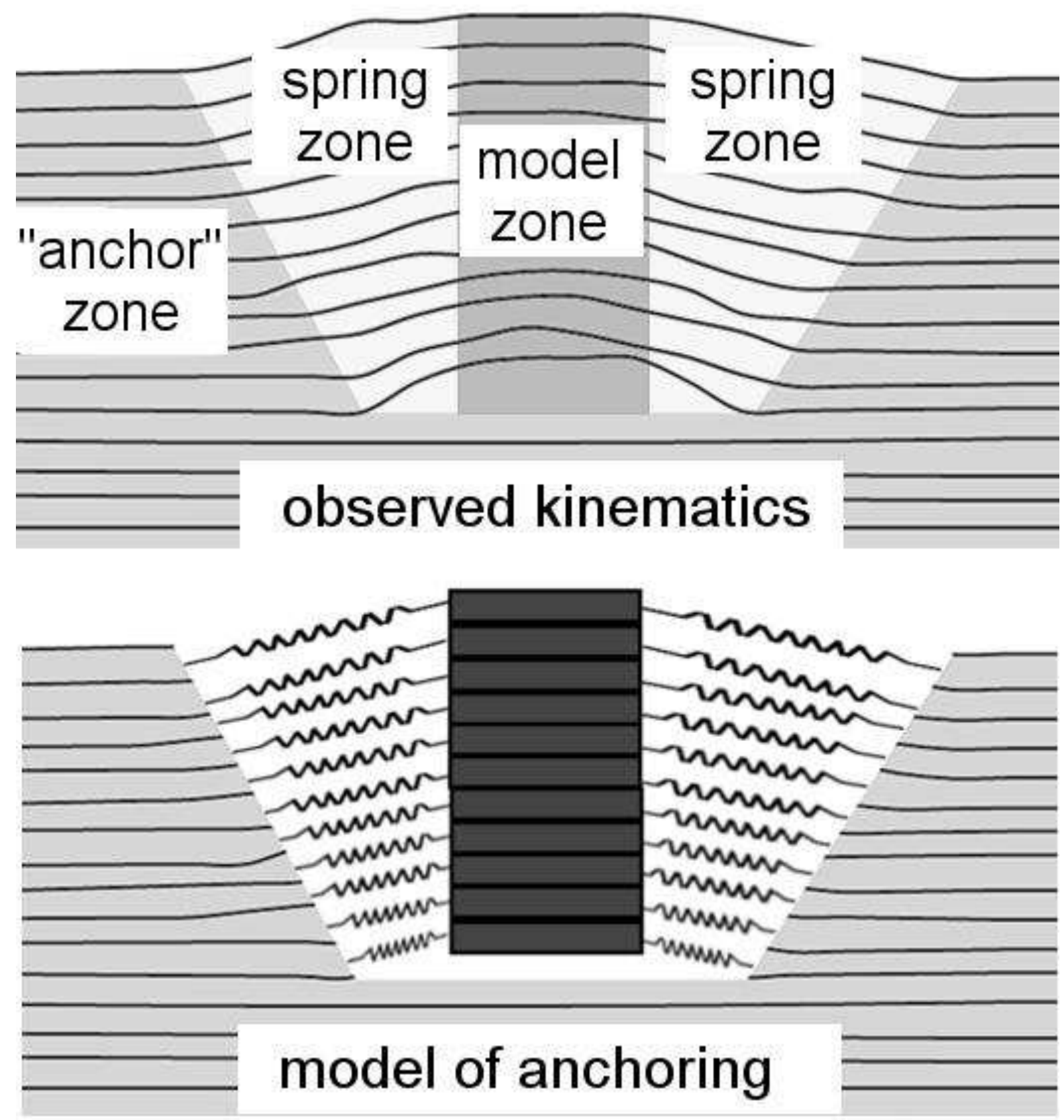

model and the improved reinforcement models (soft and hard cases).

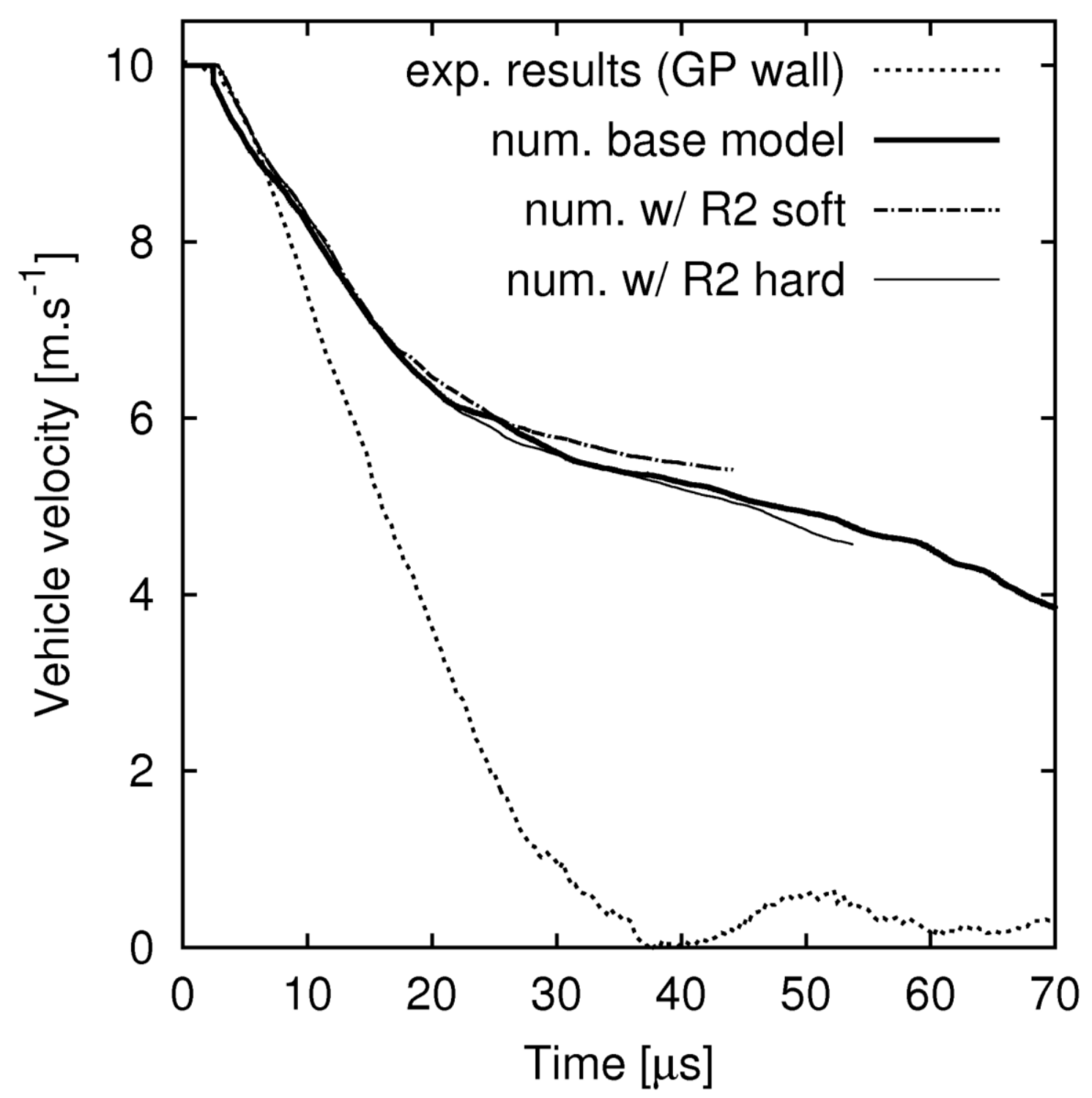


Fig. 17 - Cross-section of the modelled wall in the case of the improved reinforcement model with soft stiffness (left) and hard-stiffness (right) springs. The dotted line represents the top boundary of the reinforcement strip during impact.

751

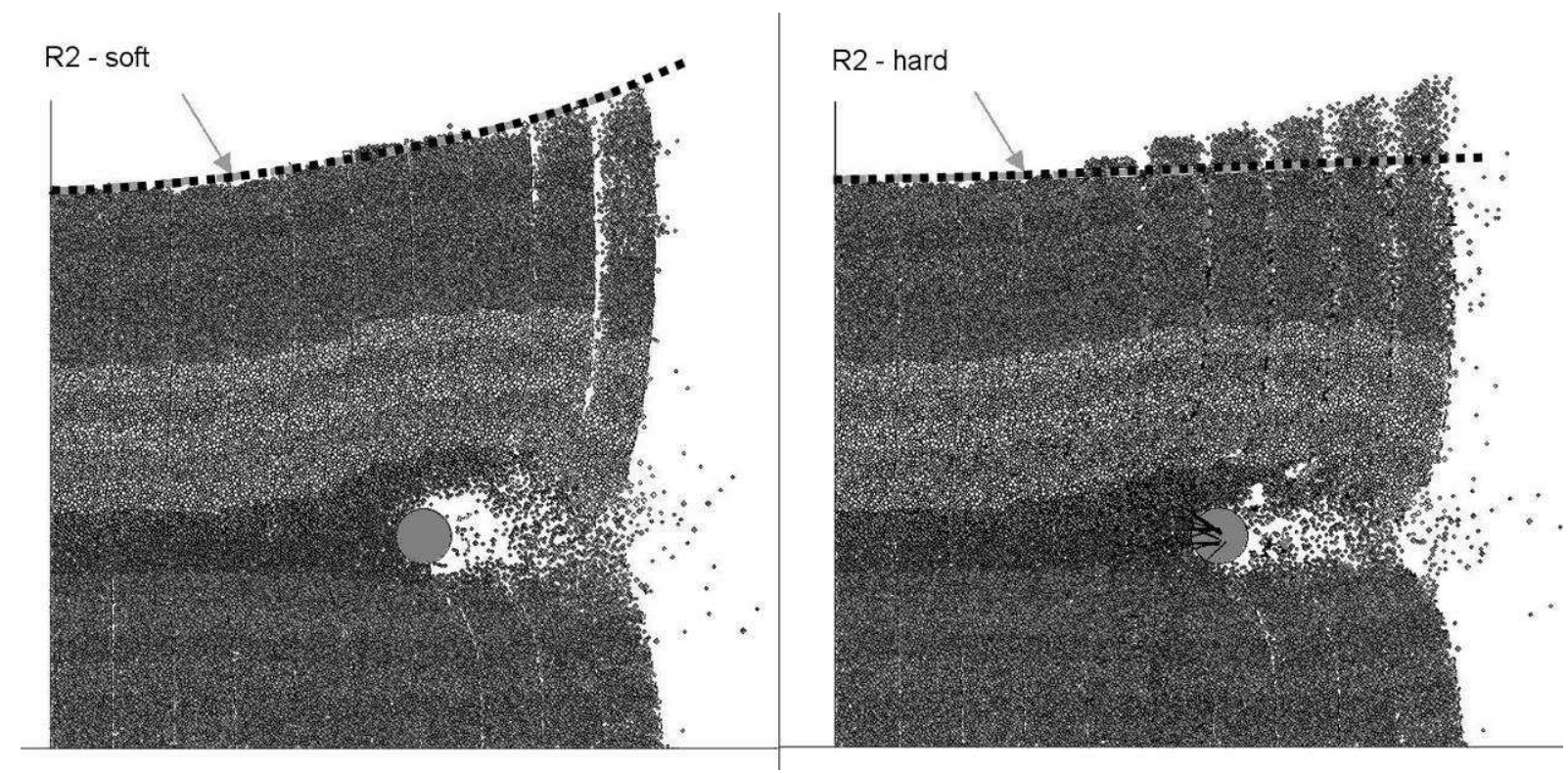


754 Fig.18 - Description of the rolling resistance model of Jiang et al. (2005)

755

756
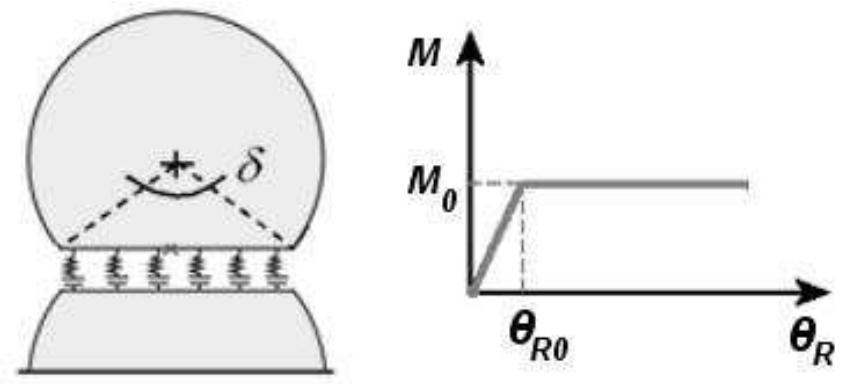


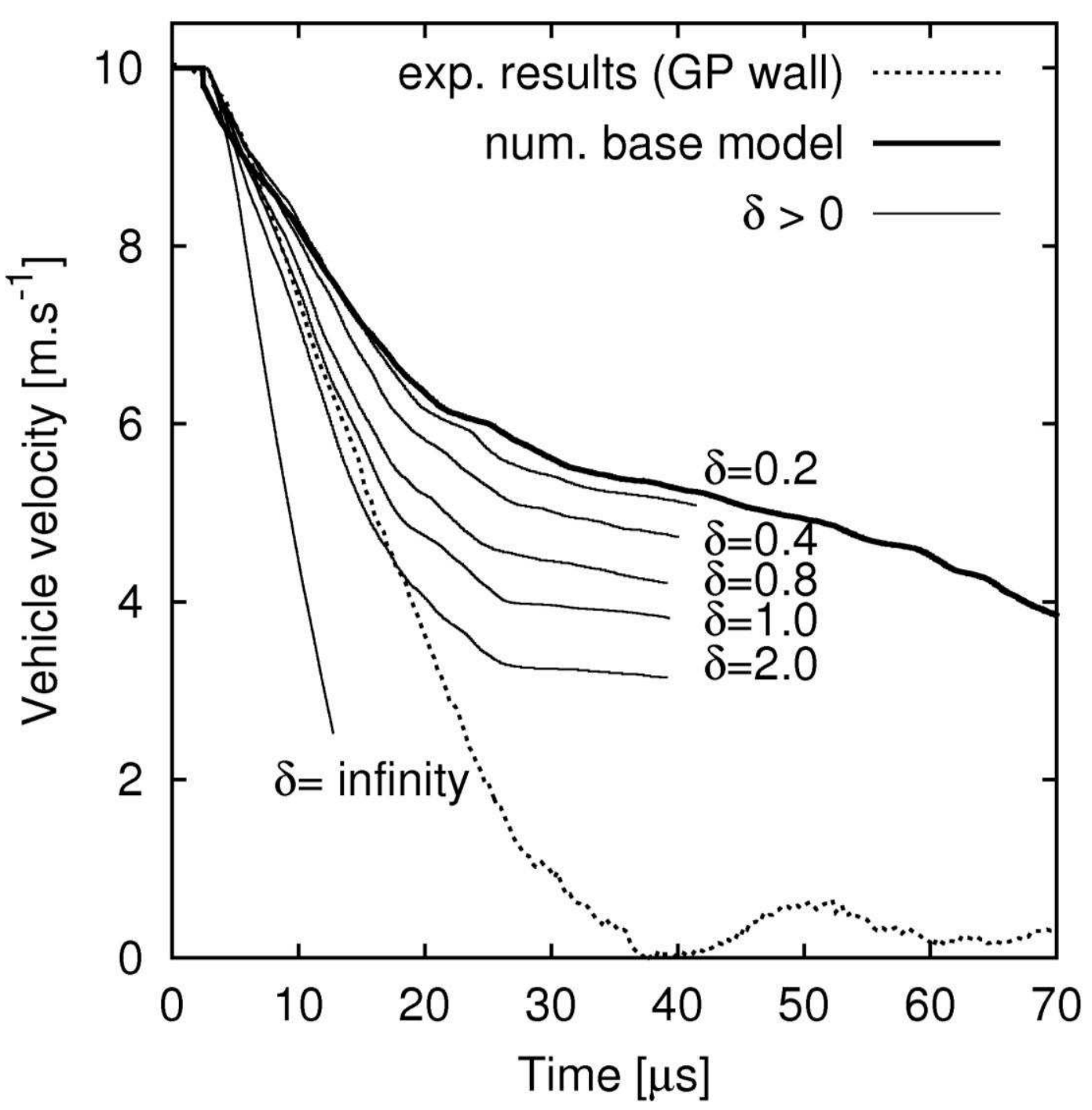

